\title{
TRANSFORMAÇÕES DA LINGUA ALEMÃ NO BRASIL
}

\section{Carlos H. Oberacker Jr.}

Durante a sua história de mais de 130 anos, os descendentes dos alemães e, principalmente por intermédio dêles, os imigrantes alemães vindos ao Brasil em época mais recente acolheram grande quantidade de palavras e expressões da língua oficial do país ${ }^{1}$. São muito mais numerosas do que se supõe ao primeiro momento; poder-se-ia até dizer que a influência da língua portuguêsa sôbre a alemã, como é falada no Brasil, não fica atrás da que tem sofrido aquela pela incorporação de têrmos indígenas e africanos, pois os neo-imigrantes alemães têm de vencer não poucos obstáculos para compreenderem os colonos radicados no país há várias gerações.

E' opinião corrente que a aceitação de palavras do novo meio está em relação com o processo de assimilação cultural ou aculturação. Não há dúvida de que tal relação existe, pois muitos dos vocábulos incorporados na língua vulgar alemã, o foram por negligência lingüística ou por influência da etnia predominante. Pretendemos, entretanto, demonstrar que numerosos têrmos foram aceitos por necessidade lingüística, decorrente não só da transplantação de comunidades alemãs para um meio inteiramente diverso, como também pelo horizonte e vocabulário limitados dos imigrantes. Para separar as palavras recebidas no processo de assimilação cultural das que o foram sòmente por, se assim podemos dizer, uma necessidade técnica de dominar o novo ambiente, distinguimos dois grupos:

1. ${ }^{\circ}$ grupo: Palavras inteiramente inevitáveis ou de adaptação aceitas por não existir na língua alemã denominação para o respectivo objeto ou atividade. Poderiam ter sido evitadas sòmente pela criação de neologismos.

2..$^{\circ}$ grupo: Enquanto o motivo para a aceitação das palavras do primeiro grupo reside no novo ambiente material, o acolhimento das do segundo depende dos próprios imigrantes, o que quer dizer que os motivos não eram objetivos, mas sim subjetivos, e que, portanto, a aceitação era, em princípio, evitável. Distinguimos dois subgrupos:

a) palavras relativamente evitáveis, ou de depauperamento, aceitas principalmente pela pobreza lingüística dos imigrantes oriundos das camadas baixas. O processo de transplantação era, entretanto, também o motivo da aceitação dessas palavras, pois as respectivas coisas e atividades sòmente aqui entraram no horizonte dos imigrantes, cabendo ao português suprir as lacunas e deficiências do vocabulário.

b) palavras inteiramente evitáveis ou de assimilação cultural pròpriamente ditas, para cujo acolhimento não existia necessidade obje- 
tiva, nem subjetiva, nem tampouco lingüística, explicando-se a sua aceitação sòmente pela influência cultural. Pressupõe a aceitação de tais têrmos geralmente certos conhecimentos da língua portuguêsa, o que não se pode afirmar com relação às palavras de adaptação. São estas principalmente as que se afiguram como índice de aculturação.

O conceito de evitabilidade ou inevitabilidade, que introduzimos aqui, é naturalmente relativo e elástico. Parece, entretanto, que por isso mesmo corresponde à realidade. Assim, por exemplo, o grau da inevitabilidade de nomes estrangeiros para plantas e animais seria muito mais baixo para um grupo de alemães emigrados para a Europa oriental do que para imigrantes vindos para a América do Sul, simplesmente por se parecerem o reino vegetal e animal da Europa oriental muito mais com os do país de origem do que os da América Meridional. Ou, enquanto para os descendentes dos colonos portuguêses a aceitação de palavras da administração e política durante a época colonial não era necessária, por ser o Brasil administrado segundo as leis e instituições do país de origem, o colono alemão encontrou aqui um Estado organizado, não podendo em absoluto deixar de recorrer a muitos têrmos dêste terreno.

A aceitação de palavras estranhas pode variar em grau, isto é, podem manter a sua pronúncia e acentuação originais ou tomar pronúncia al'emã, como também desinência alemã, ou, ainda, ser completamente germanizadas. O primeiro caso se dá principalmente onde há contacto permanente entre os que falam o alemão e os que se exprimem em português, de preferência nas cidades, vilas e colônias, em que predomine o elemento de origem lusa. Os têrmos continuam sendo palavras estrangeiras, reconhecidas e usadas como tais. No segundo caso, quando as pessoas que falam o alemão ignoram o português ou o ignoravam na época do acolhimento, não existindo possibilidade de correção na pronúncia, o imigrante ouvia uma vez só a palavra estrangeira e isto com o seu ouvido alemão, germanizando, portanto, logo o novo têrmo. Dizem, assim, "fakong" e não facão, "kujaba" e não goiaba; o vocábulo passa, assim, da órbita de uma etnia para a de outra, ficando germanizado, e a sua proveniência é desconhecida pelo povo simples, que talvez até chegue a julgar que se trata de têrmo alemão. Fakong, por exemplo, fica Fack, Kujaba Kujabe, milho Milje, tropa Tropp e Trupp, estufar stufen etc. A transformação pode ir mais longe ainda: por exemplo, quando farinha é estropiado em Farin, freio em Freh, fumo em Fumm; há mesmo casos em que a palavra é identificada parcial ou até completamente com vocábulos alemães de sentido diferente, contribuindo para esta germanização evidentemente a consonância ou seja o acôrdo musical com palavras ou sílabas da língua assimilante: barranco ou barranca se transforma em Barranke, (Ranke, rama, trepadeira), rama de aipim em Aipi-Ramme (rammen, fincar), bagaço em Bagasse (Gasse, viela, travessa), tucano em 
Tuck-Hahn (Hahn, galo) ou foice em Ruchs (rapôsa), roça em Ross (cavalo), inhame em Jammer (miséria, calamidade), cana em Kanne (jarro), estufa em Stufe (degrau), lata em Latte (sarrafo), venda em Wende (volta, transição), pasto em Bast (entrecasca, fibra), ou em Past (Pasto, pasta), mapa em Mappe (pasta), laçar em lassen (deixar), capa em Kappe (boné, carapuça), poncho em Punsch (ponche), câmara (municipal, estadual) em Kammer (também quarto pequeno), tapete em Tapete (papel pintado para forrar quartos) etc., etc.

Muitas palavras de origem portuguêsa são usadas simultâneamente em sua pureza original e com uma ou diversas declinações ou transformações alemãs. Na mesma colônia, os moradores da cidade ou da vila, que dominem a língua portuguêsa, podem pronunciar corretamente "inhame", enquanto o lavrador designa a mesma planta Jammer, como nas redondezas de Joinville, ou Jams, como na área de Brusque e Blumenau. Entre outras influências, manifesta-se aí o dialeto ou a origem regional dos colonos. Na enumeração dos vocábulos adotados procedemos, por isso, da seguinte maneira: mencionamos em primeiro lugar a palavra portuguêsa, fazendo seguir então - no caso de haver diferença na pronúncia ou terminação - entre parênteses as diversas variantes, indicando mais, antes de cada uma delas, o Estado e talvez a colônia ${ }^{2}$ em que a encontramos, sem que, com isso, queiramos dar a entender que não ocorra também alhures. Para os têrmos que sofreram grande transformação, usamos a grafia alemã, como, por exemplo, roça, Rosse, Ross.

\section{Palavras de adaptação}

O meio brasileiro era inteiramente diferente do alemão, quer quanto à natureza - clima, plantas, animais etc. - quer aos alimentos, às vestimentas, às relações sociais, econômicas e políticas. Mesmo quando estabelecidos em colônias relativamente homogêneas quanto à origem étnica, os colonos e seus descendentes não podiam escapar a uma transformação profunda em seu sistema de vida. Um mundo completamente novo invadia o horizonte dêsses imigrantes, arrancados, em sua maioria, das aldeias e das camadas inferiores do povo alemão. Desorientados diante do mundo novo que se lhes deparava, muitos teriam preferido voltar, se tal alternativa tivesse sido viável, como procede grande parte dos imigrantes do século atual.

$\mathrm{Na}$ situação de então, tendo pago o Govêrno as despesas de transporte, e sem meios próprios, só lhes restava acomodarem-se ao novo meio, no qual de nada lhes serviam a milenar sabedoria e as normas da lide campesina, no qual não encontravam nenhuma das bem conhecidas árvores, nenhum dos arbustos da terra natal, e no qual nenhuma das aves européias cantava o seu canto. Mil e uma coisas novas avultavam diante dêsses humildes imigrantes, coisas que ignoravam completamente ou com 
as quais na Europa não haviam tido contacto. Umas tantas coisas que serviam a fins conhecidos na terra de origem tinham aspecto diferente e estranho. O ambiente estrangeiro, entretanto, deveria tornar-se a pátria nova, o que obrigava os imigrantes a tomar conhecimento dêsses objetos novos, cabendo-lhes, desde logo, a dominação lingüística do novo ambiente. Poderiam consegui-lo por duas vias: ou criando palavras alemãs e, em certos casos, transferindo nomes conhecidos para os objetos estranhos, mas parecidos com coisas da pátria distante, ou aprendendo com os naturais da terra a denominação corrente no próprio país. Ambos os caminhos foram seguidos, principalmente o segundo, mas também o primeiro, e isto em medida tanto mais surpreendente quanto se aprofunda a investigação do assunto. As expressões criadas pelos rústicos colonos são muitas vêzes bem precisas e acertadas e estranhamos que até agora não se tenha tentado fixá-las. Em sua maioria, variam, aliás, de um núcleo colonial para outro, sendo, não raro, usadas paralelamente com vocábulos indígenas ou portuguêses, quiçá germanizados. Ao lado dessas criações existe a transferência de têrmos usados na Europa para coisas semelhantes ou mesmo bem diferentes. Como exemplos dos referidos neologismos enumeramos os que seguem, indicando em parênteses primeiro a tradução literal e em segundo lugar a expressão corrente, no caso de a têrmos averiguado:

Árvores, arbustos, etc.:

Nägelsbaum (RG-Laj., árvore de pregos, assim chamada por causa da forma de suas flores; cinamão); Nelkenbaum (RG-Montenegro, árvore de cravos; cinamão); Negerohrenbaum ( $R G$, árvore de orelhas de negro, por causa da forma e da côr de suas sementes; timbaúva); Affenbeerenbaum ( $R G$, árvore de bagos de macaco, assim chamam o pé da fruta de conde; ateira); Zuckerschotenbaum ( $R G$, árvore de vagens de açúcar; ingàzeiro); Futterpalme (RG.-Laj., palmeira de forragem; coqueiro); Kokehrenpalme ( $\mathrm{SC}-\mathrm{Bl}$. , f. $\mathrm{h}^{3}{ }^{3}$ ) de coqueiros e Palme, por chamarem os frutos coqueiros, em vez de cocos; coqueiro); Wollbaum ( $R G$, árvore algodoeira); Schwarzherz ( $R G$, coração preto, por ser preto o coração do tronco; guajuvira); Jochholz ( $R G$, madeira para jugo, por ser aproveitada para o jugo dos bois nas carretas; canela do brejo); Algodongbaum (RG, f. h. de algodão e Baum, árvore; o mesmo que Wollbaum); Käsbaum (RG) ou Kappesbaum (SC), (árvore-queijo ou árvore-couve; umbu), distinguindo-se no RG o "weicher Käsbaum" (árvore-queijo mole; umbu) e o "harter Käsbaum" (árvore-queijo dura; corticeira, por ter madeira dura, mas bem leve); Teebaum (RG, árvore de chá; erva-mate); Pinie (RG, p. t. ${ }^{4}$ ou trad. ${ }^{5}$ ), pinheiro, pinho, Araucaria brasiliana; também existem as designações coletivas: Teewald (RG, mata de chá; erval; no RG há um lugar chamado Teewald) e Pinienwald (mata de pinheiros; pinheiral); Kaffeeberg (ES, morro de 
café; cafèzal, nas velhas colônias alemãs do ES o café é plantado geralmente nas encostas, por ser o terreno muito acidentado; a expressão Kaffeeberg talvez tenha sido formada por analogia com "Weinberg" (vinha), palavra familiar aos primeiros imigrantes vindos do Hunsrück ou da Renânia); Lichtrohr ( $R G$, taquara-luz ou taquara clara ou transparente; cana fina usada para trançar jacás); Besenstrauch ( $\mathrm{SC}, \mathrm{SP}-\mathrm{RG}$, arbusto-vassoura, vassoura); Palmitenwedel (SC, cauda ou fôlha do palmito, coqueiro).

Musgos, liquens, bardanas e sementes:

Bocksbart (p. t. ou trad., barba de bode); Weihnachtsmannbart (SC-J., barba de Papai Noel; barba de velho ou barba de pau); Kronenbast (SC, f. h. de Krone, coroa, e pasto; capim que cresce em forma de coroa); Pfaffenläuse ou Bettelläuse (SC, SP-Riogr., piolhos de padre ou piolhos mendicantes; picão); Klebläuse (SC-J., piolhos pegosos; pega-pega); Katzenschwanz ( $\mathrm{SC}-\mathrm{J}$, rabo de gato, feto de fôlhas compridíssimas); Negerohr ( $R G$, orelha de negro; semente do timbaúva), Affenohr (SC, orelhas de macaco; idem); Zuckerschote ( $R G$, vagem de açúcar, comestível; vagem com a semente do ingàzeiro); Bugerbeere (SCJ., bago de bugre; ôlho-de-cabra, usado como adôrno, acreditam que dá sorte).

\section{Gramineas:}

Zittergras ( $\mathrm{RG}, \mathrm{SC}, \mathrm{p}$. t., erva tremedeira; usada como planta ornamental em vasos); Schneidgras ou Schnittgras ( $R G$, capim que corta as mãos e as pernas por ter as fôlhas duras e bem afiadas; capim-facão), em SC Flockenbusch (arbusto-floco, por causa da flor); Heuschreckenhafer ( $R G$, aveia de gafanhoto; espécie de aveia agreste, introduzida pelos gafanhotos da Bolívia); Schweinsborste ( $R G$, cerda de porco; grama cerdosa nos pastos; chá contra as doenças dos rins); Schweinekraut ou Schweinskraut ( $R G$, trad., erva-de-porco, beldroega, usada como remédio contra o reumatismo); Elefantengras ( $R G$, SP) ou Elefantenkapie (SCBl., trad., capim-elefante; a última palavra é f. h. de Elefant e capim); Bankrottgras ( $R G$, capim da bancarrota ou falência por indicar nas "colônias velhas" do RG o esgotamento da terra), também denominado no RG Gafanjotengras (capim-gafanhoto); Gänsegras (SC, erva de ganso; tiririca); Sauergras (SP-Riogr., capim azêdo; capim-amargoso); wilder Weizen (SP-Riogr., trigo agreste; carrapicho); Stachelkraut (SP-Riogr., erva espinhosa; caruru); Fettgras (trad., capim-gordura; indica terra boa); Schleppgras ( $R G$, capim rasteiro; talvez pelo sistema de se multiplicar); Bienenkraut ou Bienengras (SP, erva ou capim de abelha, por servir para pegar enxames de abelhas; erva cidreira); Lagartenkraut (f. h. de lagarto e Kraut, erva; planta usada para chá contra a gripe); Flusskapie (SC-B1., capim do rio; forragem). Sommergras (SC-B1., 
capim de verão, por crescer principalmente nesta estação do ano; ervamá), também chamado Sommerbast (SC-B1.: f. h. de. Sommer, verão, e pasto); Menz-Gras ( $\mathrm{SC}-\mathrm{Bl}$., capim do Menz, introduzido por um tal Menz); Kuh-, Pferde- e Mulen-Graniuve (?) (arbusto de vaca, cavalo e mula; três plantas diferentes que servem de forragem para o resp. animal); Futterkanne (SC, f. h. de Futter, forragem, e cana; cana para ração e também para fabricação de açúcar); Salzkanne (SC, f. h. de Salz, sal, e cana, cana-sal, cana azêda, que serve sòmente para forragem); Stinkcapim ( $\mathrm{SC}-\mathrm{J}$.: capim fedorento).

Flores, legumes e frutas:

Waldlilie (RG, lírio do mato; bilbérgia); Elfuhrblume (ES, flor das onze horas; trad., onze-horas); Passionsblume (RG, flor da paixão; flor do maracujá); Papageienblume ( $\mathrm{SC}-\mathrm{J}$., flor de papagaio; gladío10); Batatenblume ( $R G$, f. h. de batata (doce) e Blume, flor; nome dado à dália, devido à semelhança dos tubérculos); Federblume e Pusteblume (SC-J., flor de pena ou flor-sôpro); Fahne (RG, bandeira; pendão do milho; usa-se a expressão: Die Milje steht in Fahnen, o milho está em bandeiras); Milje- e Mandiokstengel (RG, f. h. de milho, mandioca e Stengel, caule); Miljeestorz (RG, f. h. de milho e Storz, palavra dialetal significando sabugo); Wachsblume (SP, flor de cêra); Butterkohl (SP, couve-manteiga, trad.); Pastapfel (SC, maçã do pasto, fruto de um arbusto agreste); Zuckerschote ( $R G$, vagem de açúcar; semente e frutas do ingàzeiro); Affenbeere ( $R G$, bago de macaco; fruta de conde); Tannenzapfen (RG, p. t., pinha; pinhão); Mispel (SC-B1., p. t., ameixa néspora); Ananas (p. t. para o abacaxi). Laranjas: Nabellaransche ou Nabelorange (RG, f. h. de laranja, Orange e Nabel; laranja-umbigo); Blutlaransche (RG, f. h., laranja-sangue, laranja com pingas vermelhas na carne; tangerina?). Bananas: Zuckerbanane (SC-J., banana-açúcar); Goldbanane (SC-B1., trad., banana-ouro); Zwergbanane (SC-J., trad., banana-anã, banana-petiça); Petissbanane (SC, f. h. de petiça e Banane); Apfelbanane (SC-J., trad., banana-maçã); Feigenbanane (SC-J., trad., banana-figo).

\section{Animais:}

Waldhund (SC, trad., cachorro do mato); Sandhase (RG, coelho da areia; preá; v. também palavras injuriosas); Goldhase ( $\mathrm{SC}$ : coelho de ouro; aguti); Wasserchwein (porco dágua; capivara); Mäuseschlange (SC, cobra dos ratos, cobra rasteira; caninana); Stinktier ( $R G$ ) e Beutelratte (SC, p. t.) (bicho fedorento ou rato com bolsa; gambá).

Aves:

Wasserhuhn ( $R G$, galinha dágua; saracura); Barattenfresser ( SC, comedor de baratas; corruíra); Bienenfresser ( $R G$, comedor de abelhas, 
espécie de sabiá); Bananenfresser (comedor de bananas); Amsel (RG, melro; p. t., sabiá); Blaujack ( $\mathrm{SC}-\mathrm{J}$., paletó azul); Lausvogel ( $\mathrm{RG}$, pássaro piolhento ou também pássaro miserável, pois põe os ovos em ninho alheio; alma de gato ou anum branco); Pasthexe (SC, f. h. de pasto e Hexe, bruxa; anum prêto); Lauseonkel (SC-J., tio catador de piolhos, pois colhe os bichos das costas do cavalo; das vacas etc.; anum prêto); Aasvogel ( $R G$ ) e Aasgeier (SC) (aves ou abutre comedor de carniça; urubu); Waldschmied ou Schmied (RG, SC, trad., ferreiro do mato ou ferreiro; araponga); Waldhuhn (SC, galinha do mato; macuco); Webervogel ( $R G$, pássaro-tecelão, pois, "tece" um ninho comprido de crina; japim); Pfeffervogel (RG) ou Pfefferfresser (SC, SP) (pássaropimenta ou comedor de pimenta; tucano); Geckefasan ou Schageragag ( $R G$, faisão almofadinha ou jacu); Dreckbauer ( $R G$, construtor de barro, por fazer o seu ninho com barro; João-de-barro ou forneiro); Lauskrämer ( $R G$, vira-piolhos, espécie de pêga; vira-bosta?); Scherenschleifer ( $R G$ ) ou Scherenschwalbe (SC-J.), (amolador de tesouras ou andorinha de tesouras; terousa-do-campo?); Karapattenfresser ( $\mathrm{SC}$ B1., f. h. de carrapatos e Fresser, comedor); Perdieshuhn e Perdieshahn (galinha perdiz e galo perdiz; perdiz e perdigão).

\section{Peixes:}

Speckkopf (RG, cabeça de toucinho; cará); Dickbauch (SC-J., barriga gorda, que, sendo tratado com cócegas, se infla até arrebentar; baiacu).

\section{Insetos:}

Miljebock (RG, f. h. de milho e Bock, bode; besouro do milho; caruncho); Maisbock (SC) e Maiskäfer (SC-J.) (idem); Schweissbiene (RG: abelha de suor; abelha-mosquito); Fleischbiene (RG, abelha de carne; vespa prêta que aparece quando se abate um animal; Stahlbiene ( $R G$ ) ou Stahlwespe (SC-J., abelha-aço ou vespa-aço, por causa da côr); Hundsbiene ( $R G$, abelha de cachorro; espécie de abelha indígena); Haarwickler (RG) ou Haarbiene (SC, enrola-cabelos ou abelha-cabelo, que se enrola no cabelo da gente); Sandfloh ( $R G, S C$, pulga de areia; bicho-do-pé); Kampochse ( $R$ G, boi do campo; saúva); Schlepper ou Schleppameise ( $R G$ e SC) ou Tragameise (SC-J.), distinguindo-se em SC-J. ainda Tag- e Nachttragameise ou Tag- e Nachtschlepper (carregadeira, formiga-carregadeira, carregadeira diurna e noturna; formiga-mineira ou mineiro); Wanderameise ( $R G$ ) ou Wanderer (SC-J.) (formiga viandante ou viajante, peregrino; formiga-de-correição), Fettameise (SC-J., formiga de gordura; formiga vermelha e muito mordaz); Erdfloh ( $R G$, pulga da terra, do chão; parasita da planta de tabaco). 


\section{Utensílios e outros instrumentos:}

Holzbock (RG, cavalete de madeira, espécie de sela para transportar cargas); Tragebock (SC) ou Kalger- e Kargerbock (SC, f. h. de carguejar e Bock, cavalete); Abzieher (SP, rôdo); Moskitonetz (RG, f. h. de mosquito e Netz, rêde; mosquiteiro); Farinmühle (RG, f. h. de Farin, farinha, e Mühle, moinho; engenho de farinha de mandioca); Ziepo-Besen (SC-J.: f. h. de cipó e Besen, vassoura; vassoura de cipó; Ziepo-Schrubber (SC-J., f. h. de cipó e Schrubber, escôva; escôva de cipó); Lischoeimer (f. h. de lixo e Eimer, balde; balde para lixo, mais conhecido é Lischolatte, de lixo e lata); Kehrichtlatte (SC-B1., f. h. de Kehricht, lixo, e lata, lata para lixo); Lischowagen (f. h. de lixo e Wagen, carro; carro que transporta o lixo); Kabinhacke (SC, de enxada e kabinen; enxada para capinar); Putzhacke ( $R G$, enxada para limpar, isto é, capinar); Buschsiche1 ou Puschsichel ( $R G$, de foicinha e capoeira, foicinha para a capoeira ou o arbusto, Busch; Pusch pode ser a palavra estropiada Busch ou derivarse de puxar; foice), também chamada Puschhacke ( $R G$, enxada para a capueira ou enxada de puxar); buschen ou puschen (o respectivo verbo, que tanto pode provir do substantivo alemão Busch, como do verbo português puxar; trabalhar a foice; foiçar); Kargerkorb (SC: cesta para carguejar; jacá); Faringeschirr (SC-B1., f. h. de Farin, farinha, e Geschirr, vasitha; engenho de farinha de mandioca); Farinkessel (SC-B1., f. h. de Farin, farinha, e Kessel, caldeira; tacho para fazer farinha de mandioca); Zuckergeschirr ( $\mathrm{SC}-\mathrm{Bl}$., vasilha de açúcar; tacho para a produção do açúcar e da "chimia"); Kannequetsche (SC-B1., f. h. de Kanne, cana, e Quetsche, prensa; prensa para fazer guarapa) também chamada Guarapenquetsche (SCB1., f. h. de guarapa e Quetsche, prensa); Tabakofen (RG-Laj., forno de tabaco; estufa para o tabaco); Tamankennägel ( $\mathrm{SC}-\mathrm{B} 1 ., \mathrm{f}$. h. de tamanco e Nägel, pregos; tachas de tamanco; preguinhos com cabeça chata); Palmitenbude (SC-Bl., f. h. de palmito e Bude, barraca; barraca feita de palmitos); Foicenstiel (SC-Bl., f. h. de foice e Stiel, cabo, cabo de foice); Miljestroh (RG., f. h. de milho e Stroh, palha; palha de milho); Maisstroh (SC, idem); Zigarrblatt (RG: palha de milho, preparada para cigarros); Esel (RG, SC, SP, burro; cana de vento); Ansteckmesser ( $R G$, faca para enfiar na cinta; facão); Waldmesser ( $R G$, faca para o mato; facão); Buschmesser (SC-Bl., faca para a capłueir'^; facão); Pelzgurt (RG, cinto para o pelego; sobrecincha); Steckportehre (RG) e Steckportiëre (SC-Bl., f. h. de Stecken, enfiar, e porteira; porteira de troncos finos colocados horizontalmente em dois cavaletes aos lados); Windmühle (RG., p. t., moinho de vento; aparelho manual para a limpeza do feijão), também é usado o verbo windmühlen, Teepumpe (RG., bomba de chá; a bombilha para o chimarrão); Teekuje (RG, cuia de chá, isto é, para o chimarrão). 
Alimentos, bebidas, estimulantes etc.:

Puffmilje on Bockmilje (RG., f. h. de milho e puffen, estourar, ou bocken, pular; milho-pipoca); Maisfarin (SC, P, f. h. de Mais, milho, e Farin, farinha), Kochmelade (RG, SC, f. h. de kochen, cozinhar, e melado; segundo outras informações, a primeira palavra deve ser derivada de côcho, gamela, melado do côcho); Zuckerrohrschmier ( $R G$, melado de cana, em estado semi-sólido, para passar no pão; no $\mathrm{RG}$ o mesmo que Kochmelade; o melado é misturado com qualquer fruta, formando-se assim os vocábulos: Melonenschmier (melado de melancia); Laranschenschmier (de laranja); Boberschmier (de abóbora); Pfirsichschmier (de pêssego); Marmellenschmier (de marmelo); Batatenschmier (de batata doce); Pflaumenschmier (de ameixa) etc. Kochkarah e Brotkarah ou Backkarah (SC-J., f. h. de cará e kochen, cozinhar, e Brot, pão, ou backen, cozer ao forno); Palmitenkohl e Palmitensalat (de SC para o norte: f. h. de palmito e Kohl, couve, e Salat, salada); Mate-Tee ${ }^{6}$ (RG, chá de mate, erva-mate; chimarrão adoçado); Bittre ou Grüne ( $R G$, o "amargo" ou o "verde"; chimarrão não adoçado, de fato a palavra espanhola chimarrão significa agreste, amargo); Matelutsch ( $R G$, f. h. de mate e lutschen, chupar, o ato de tomar chimarrão; a roda de amigos e conhecidos para tomar chimarrão); Spritzbier (RG: cerveja espumante, feito de gengibre, mel e lêvedo; cerveja de gengibre); Schinschibier (SC, f. h. de "gengi", gengibre, e Bier, cerveja); Maiszigarre (SC, cigarro de milho, cigarro de palha de milho); Paljezigarre ( $R G$ : $f$. h. de palha e Zigarre, cigarro); Schuppentabak ( $R G$, tabaco do barracão, isto é, estufado no alpendre); Ofentabak ( $R G$, tabaco do forno, sito é, secado na estufa); Stufentabak (SC-B1., f. h. de estufa e Tabak, tabaco); Rollefum (também, talvez estropiado, Strollefum) ( $R G$, fumo do rôlo, fumo em corda).

Animais domésticos :

Puschochse (SC-B1., f. h. de puxar e Ochse, boi; boi para puxar, v. também palavras depreciativas; Marschgänger ( $R G$, que anda marcha; cavalo marchador); Trottgänger ( $R G$, que anda trote; cavalo troteador); Meladeschimmel ( $\mathrm{SC}-\mathrm{Bl}$., cavalo da côr do melado).

\section{Indumentária:}

Mesklahose (RG, f. h. de mescla e Hose, calças; calças de mescla); Flackerponsch ou Flackerpunsch (RG, f. h. de flackern, tremular ao vento, e poncho) e Kreditponsch ou Kreditpunsch ( $R G$, f. h. de Kredit, crédito, e poncho, têrmos para ponchos usados como adôrno com o intuito de causar impressão e conseguir um certo fim).

\section{Doenças:}

Affenkrankheit (SP, trad. doença de macaco); Landeskrankheit ( $R G$, trad. mal-da-terra; amarelão); schlechte Krankheit (SC, doença ruim; 
sífilis); Wildfeuer (SP, trad.: fogo selvagem; pênfigo foliáceo); Klimawunde (SP, chaga do clima; doença de aclimatização dos imigrantes).

Designações para pessoas:

Kannespalter (SC-Bl., racha-cana; avaro, sovina); Eierfresser (SCBl., comedor de ovos; pessoa que vive à custa de outros); Kapiläbub (RG, f. h. de capilé e Bub, menino, criança; assim chamam a quem fàcilmente fica bêbedo ou não toma álcool); Deutschländer (RG, alemão da Alemanha, imigrante novo; quem nasceu na Alemanha); Neudeutscher e frischer Deutscher (SC, alemão novo) ${ }^{7}$; Drübigdeutscher (RG, drübig é palavra dialetal; alemão dalém-mar, da Europa); Deutschbrasilianer (teuto-brasileiro; brasileiro de descendência e língua alemã); Musterreiter (RG, talvez p. t., cavaleiro com amostras; caixeiro-viajante a cavalo); Brummer ( $R G$, resmungão, rezingão, designação dada aos soldados da legião estrangeira de 1850, aliciada na guerra contra Rosas; diz-se que os legionários usavam para grandes moedas de cobre com que eram pagos o nome "Brummer", alusão ao som baixo-vibrante que produziam quando jogadas ao soalho, sendo a denominação transferida depois para os próprios mercenários, talvez porque resmungassem (brummen), devido à sua sorte pouco invejável, ou por terem de cumprir o seu contrato (abbrummen) ou, ainda, por ficarem, muitas vêzes, no xadrez para cumprir penas (abbrummen); Hiesiger (p. t., nativo, natural da terra).

Nomes depreciativos e injuriosos:

Blauer (RG, usado em geral no dialeto do Hunsrück: "Bloher"; isto é, de côr azul, de côr; Grüner (ES, de côr verde, de côr; têrmo equivalente ao do RG); Eidechs(e) (SC-B1., lagarto, lagartixa); Barankenhocker ou Barankenhucker (SC-Bl., f. h. de barranco e hocken, estar sentado, ococorado; referência ao caboclo que, não possuindo terra própria, vive junto aos barrancos da estrada ou do rio); Farinbauch (RG, SC, f. h. de Farin, farinha de mandioca, e Bauch, barriga; idem); Heckenschlupfer ( $R G, S C$, que se enfia na capueira, isto é, um pobre diabo que não tem terra própria; idem); Gravatáschlupfer (RG, f. h., que se enfia nos gravatás, na terra pobre e cansada do colono; idem); Heckenbewohner (ES, morador da capueira, da macega; idem); Schlammbuger (SC, f. h. de Schlamm, lôdo, e bugre; bugre do lôdo, da lama); em SC-J. distinguem entre o Schlammbugger o Waldbugger (o bugre da zona alagada e o da zona do mato); Bohnenfresser ou Pirongfresser (SC, comedor de feijão ou pirão; refere-se ao caboclo); Bohnenbauch ou Pirongbauch (SC, barriga de feijão ou de pirão; idem); Sandhase (SC_J., preá); Pfefferkopf (ES, cabeça de pimenta; alcunha dada sòmente ao negro); Puschochsen ( $\mathrm{SC}-\mathrm{B} 1$ : vide animais domésticos; designação depreciativa dada ao colono pelo habitante da cidade); Pommernknoten (SC-B1., pomerano-vilão; designação dada ao colono descendente de pomeranos). 


\section{Diversas palavras avulsas:}

Kamp (p. t., campo; na $\mathrm{Al} .{ }^{8} \mathrm{Kamp}$ significa uma área agrícola cercada); Kampland ( $R G$, terra de campo; os campos naturais, que em geral não servem para a colonização e a lavoura); Fogettengeld (RG, f. h. de foguetes e Geld, dinheiro; pequenos presentes em dinheiro que se dão ao "Hochzeitsbitter", cavaleiro de chapéu enfeitado com fitas de diversas côres etc., que convida parentes e amigos para um casamento - a fim de comprar foguetes para estourar no dia festivo); Knochenspiel (RG, jôgo de osso, com um osso quase cúbico); Surprêsa-Leute (RG, f. h. de surprêsa e Leute, gente; pessoas que aparecem por ocasião de um noivado ou aniversário para exibir-se com certas surprêsas, canções, poesias, música, peças teatrais etc.); Tiefe ( $\mathrm{SC}$, trad., fundos, terrenos nos fundos dos lotes coloniais; o têrmo passou em SC para o português como tifa); Staatsschule (RG, escola estadual, pública); Innere (trad., interior); Schmalzbauer ( $R G$, colono cuja receita principal provém da criação de porcos e da produção de banha); Schmalzernte (RG, safra de banha, época em que se matam os porcos para a produção de banha); schwarz sprechen (ES, falar prêto ou negro; falar português), Rentensteuer (trad. errada de imposto sôbre a renda; Rente em alemão significa pensão); Konkretbrücke (f. h. de concreto e Brücke, ponte; ponte de concreto); Besitztitel (f. h. de Besitz, propriedade, e Titel, têrmo, aliás, desconhecido em alemão no sentido de documento, título, título de propriedade); Wählertitel (f. h. de Wähler, eleitor, e Titel, título; título de eleitor); Landpapiere (papéis do terreno, lote colonial, título de propriedade); Balkonverkäufer (f .h. de balcão e Verkäufer, vendedor; balconista); Friosgeschäft (SP, f. h. de frios e Geschäft, loja); Friosschrank (SP, f. h. de frios e Schrank, armário; balcão de refrigeração); puscha noch einmal (interjeição, f. h. de puxa e noch einmal, mais uma vez), Kompaderschaft e Kommaderschaft (RG, f. h. de compadre, comadre e o sufixo alemão "schaft"; as relações entre os compadres, as comadres e os afilhados ou afilhadas e seus pais); Stehfila e Sitzfila (SP, f. h. de stehen, ficar em pé, sitzen, ficar sentado, e fila; fila para viajar sentado no ônibus e fila dos que ficam em pé); Kammerhaus (RG, casa da câmara; prefeitura); Moskitenjäger (SC-Bl., f. h. de mosquito e Jäger, caçador; funcionário do Serviço da Malária).

E' de supor-se que o número de palavras alemãs criadas pelos imigrantes ultrapasse em muito os aqui enumerados, pois até hoje ninguém se ocupou com o fenômeno interessantíssimo que é a fôrça de criação lingüística daquela gente primitiva, que, entretanto, não podia dominar tudo o que de novo se lhes deparava na pátria adotiva. Na maioria dos casos, aquêles imigrantes, com sua bagagem cultural relativamente modesta e seus restritos conhecimentos da língua alemã, ficavam desamparados perante o mundo novo, a começar pela exuberante natureza, com a qual 
desde logo deveriam viver em íntimo contacto, quer de modo amigável, quer hostil. Da relação dos vocábulos alemães aqui criados a grande maioria se referia à natureza; entretanto, as novidades que esta oferecia eram tantas que justamente nesse terreno se impunha também a aceitação de palavras portuguêsas e indígenas. O mesmo, aliás, se dera séculos antes, com os lusos, que tiveram de adotar as designações índias, como o prova o fato de a maioria dos nomes de plantas e os animais brasileiros serem de origem tupi. Damos, portanto, no que segue, sòmente exemplos dêsse processo de ajustamento ao ambiente novo, pois quase tôdas as plantas, todos os arbustos, frutos, animais, aves, peixes, insetos, gramíneas etc. são chamados por seus nomes portuguêses ou indígenas, e mesmo quando se criaram palavras alemãs, aquêles também são conhecidos e usados, muitas vêzes como forma estropiada e germanizada. Mencionamos sempre em primeiro lugar as palavras primitivas e depois, em parênteses, se existe e é essencialmente diferente, a pronúncia ou a variante teuta, usando neste caso a ortografia alemã.

Plantas:

Figueira (Figehr), pinheiro (Pinjehr, Pinjehrebaum), aroeira, cipó, butiá, canela, araçá, coqueiro (Kohehre), ipê, peroba, cinamão (v. Nägelsbaum e Nelkenbaum), imbuia, jequitibá, caruru, jacarandá, mata-pasto (SC., Matapast, Matabast, Mattepast, Mattebast) taquara, taquaruçu, louro, avenca, samambaia, três-marias, capim (SC: Kapie, RG: Kaping), grama (Gramme), pega-pega (SC: Pegepege), malmequer, mimosa, bracatinga, cráá, sapé, santa-fé, macega, purungo ou porongo (RG: Prunke, usado para a cuia; também se designam assim os seios da mulher); copode-leite (SC, SP); bico-de-papagaio, tucum ${ }^{9}$, rama de aipim (SC: Aipiramme).

Animais e aves:

Saracura (Wasserhuhn); macuco (SC: Makuk; v. Waldhuhn); jacu (v. Geckefasan ou Schageragag), aguti (v. Goldhase), lontra, onça (Onze), paca (SC: Backe, RG: Pack; no vale do Itajaí há um ribeirão (Bach) chamado Packabach), periquito (Perekitt), arara, uru, urubu (v. Aasvogel ou Aasgeier), tucano (Tukan, também pronunciado Tuck-Hahn em SCJ.; v. Pfeffervogel e Pfefferfresser); anu (v. Lauseonkel), pica-pau, queroquero (também chamado Kiebitz), tico-tico ${ }^{10}$ (RG: Tickotick e o diminutivo Tickotickche), araponga (v. Waldschmied ou Schmied), bem-tevi (cuja voz é interpretada no ES como "Siehstemi?", estás-me-vendo?, ou no RG "s'ist zuviel", é demais); perdiz (v. Perdieshuhn e Perdieshahn), sabiá (v. Amsel), gavião (RG: Kabiong; também Habicht), João-de-barro (v. Dreckbauer), beija-flor, jacu (também Fasan), tatu ${ }^{11}$, tamanduá, lagartixa (Lagartisch), lagarto (Lagart), gambá (v. Stinktier), rapôsa ( $P$ : Rapose; no sentido de gambá), jacaré, jaguatirica, jararaca (Scha- 
raracke; SC: Scharacke; $\mathbf{R G : ~ u s a d o ~ p a r a ~ d e s i g n a c ̧ a ̃ o ~ d e ~ q u a l q u e r ~ c o b r a ) , ~}$ anta (Ante), mico, capivara (RG: Kapiwar), javali, quati (Kwatie) ${ }^{12}$, pintassilgo ( $R G$ : também se usa o diminutivo alemão Pintasilbche), sanhaçu, sucuri, cascavel.

Peixes:

Bagre (SC-J., Bager), lambari, traíra (Trahier), jundiá, cascudo (Kaskude), cará (v. Speckkopf), jaú, piava, dourado, capim-cará (SCJ.: peixe que vive à beira dágua, escondendo-se sob o capim) ${ }^{13}$.

Insetos:

Gafanhoto (Gafanjot), barata (Baratte), mosquito (Moskite), pernilongo, saúva, cupim (ES: Kupie), carrapato (Karapatte), maribondo (Mariebonde), quenquém, borrachudos (Borraschuden, SC-J.: Pattaschutten), broca (bicho do café).

Frutas:

Lima (Lime), laranja (RG: Laransch), bergamota (RG e SC) (Bergamotte), tangerina (SC e ES) (Tangerine), mimosa (P) (Mimose), mexerica (SP) (Meschericke), mandarina (Pernambuco: Mandarine, assim também na Alemanha), ameixa (néspora) (Amesche, v. Mispel), carambola, maracujá, caqui, abacaxi (Backaschie; v. também Ananas), butiá, pinhão, (v. Tannenzapfen), araçá, goiaba (Goijabe, Kujabe), mamão, abacate (Abakat), marmelo (Marmelle), manga, pitanga, jabuticaba (Schabotikabe), laranja-umbigo (RG: Umbigo), laranja-Bahia, laranja-do-Rio, laranja-natal, laranja-lima, laranja-pera etc. Também para as variedades do limão se aproveitam as designações portuguêsas: limãogalego, limão-siciliano etc.); o mesmo acontece com as variedades das bananas, usando-se nestes casos - se não há tradução - a palavra inteiramente portuguêsa: banana-maçã, banana-ouro, banana-prata, bananada-terra etc.; côco (RG: Koko, SC-B1.: Kokehre, de coqueiro).

As árvores e os arbustos frutíferos não são em geral chamados pelo nome português com as terminações "eiro" ou "eira"; anexa-se ao nome do fruto a palavra Baum (árvore) ou Strauch (arbusto): Ameschenbaum, Schabotikabenbaum, Butiapalme etc.

Plantas cultivadas:

Naturalmente a nova terra com o seu clima diferente transformou a cultura agrícola do imigrante, pois as plantas cultivadas na Alemanha aqui em geral não medravam. Em lugar de trigo era preciso plantar milho, o trigo brasileiro, a batata inglêsa foi substituída pela mandioca e outras plantas tuberosas, a beterraba pela cana de açúcar.

Mandioca (Manjok, Mandiok), aipim (RG: Eiping, SC: Eipie, Eibie, perto de Bl. existe um "Aipimberg", morro do aipim), inhame 
(SC: Jams, SC-J.: Jamma e Jammer, SC-B1.: Injam e Jamma), cará (SC: v. Brotkarah, Backkarah e Kochkarah), taiá, taioba ${ }^{14}$, feijão (no sentido de feijão prêto ou mulatinho); tupi ( $R G$ : feijão mulatinho em SP, feijão pardo), batata ( $R G$ : Batate, no sentido de batata-doce, enquanto a batata inglêsa ou batatinha é designada com a palavra alemã, Kartoffel) ${ }^{15}$, abóbora (RG: Bobra, Bobre, Bober), amendoim (SC e P-C.: Mandowie, SP: Mengdowieh), (milho)-pipoca (Pockmilje, Pipocken, v. Puffmilje e Bockmilje), sabugo (SP: Sabuken SC: Ziehpokken, RG: Sabuck, v. também Miljestorz), espiga (SP: Spigen), palha (RG: Palje, no sentido de palha de milho, v. Miljestroh).

\section{Alimentos:}

Também na alimentação era preciso sujeitar-se ao novo ambiente. Na cozinha e na mesa apareciam então: palmito (v. Palmitenkohl e Palmitensalat), charque, carne sêca (ES: Karneseck), bacalhau, feijoada (Feschoade), abobrinha, chuchu (RG, SP), machucho (SC: Maschusche), pimentão, farinha de mandioca (Farin; ao passo que a farinha de trigo é designada com a palavra alemã Mehl ou Weissmehl, RG: farinha branca); em SC e $\mathrm{P}$ conhecem-se também as expressões Maisfarin, farinha de milho, e Mandiokfarin, farinha de mandioca; pirão ${ }^{16}$, beiju, tapicca ('Tapiok), polvilho (Porwilje, Porwil), araruta (Ararut), fubá, maisena, rapadura ( $\mathrm{RG}$ : Rapadur); cocada (Kokade), marmelada (Marmelade, palavra usada na Al. para qualquer doce em estado semi-sólido para passar no pão, enquanto no Brasil distinguem: goiabada (Kujabade), bananada (Bananade), pessegada (Pessegade) etc.), melado (Melade, v. Kochmelade); cozido (P-C, camarão, canjica (Kanschick, Kaschick), cuscuz, pão-de-ló, farofa ${ }^{17}$.

\section{Bebidas:}

Chimarrão (v. também: Bittre, Grüne; também se diz Matteschimarong, $\mathrm{RG}$ ), mate ( $\mathrm{RG}$ : Matt, Mate, v.: Mate-Tee), cafèzinho, média (SP, café com leite, café preparado pelo sistema brasileiro, sendo a metade de leite; o alemão o prepara menos concentrado ajuntando conseqüentemente menos leite), taça ( $R G$-PA.: no mesmo sentido como média em SP; têrmo talvez oriundo da palavra alemã Tasse), cachaça ( $R G$ : Kaschass), pinga (SP, usado em alemão como subst. masc.), refresco ( $R G$ : vinho tinto com água e açúcar), sangria ( $R G$ : Sangarie, o mesmo que refresco), limonada (Limonade), laranjada (Laranschade), gasosa ( $\mathrm{RG}$ : Gasose, Gasoos), água-tônica, guaraná, capilé (v. KapiläBub), batida, garapa (Garap); caipirinha (SP).

Organização colonial:

O sistema de convivência entre os colonos era completamente diferente do da Europa, onde moravam em aldeias, com os campos dissemi- 
nados pelos arredores; aqui moravam distantes um do outro, cada colono no seu lote, às vêzes longe do centro da comunidade.

Picada (Pikade), (usado com o nome da picada, por ex: Picada Nova), pique (RG: Pick, Picks), linha, colônia (Kolonie, Kolenie; no sentido da propriedade ou lote do colono, bem como para significar a região habitada por colonos; na Al., a palavra designa apenas uma possessão territorial ou a aglomeração de estrangeiros de certa nacionalidade no exterior); travessão, lote (Lotte, subst. fem.), sede, patrimônio (ES, MG), quadra (RG: Quader), emancipação (Emanzipation), matriz, vigário, venda ( $R G, S C, P$; de venda derivaram Vendist dono de venda), boliche bolicheiro, botequim, domingueira (SC).

Da mesma forma, a língua reflete as mudanças na economia do colono:

Roça (Rosse, Ross), roçar (rossen, rossieren, Rosse machen), plantação (RG: Plantasche), capueira (RG: Kapowere, Kapoër; SC: Kapawera, Kapewer, Kapere), capueirão, potreiro (RG: Potrehr), pasto (SC: Past, Bast), cêrca (SC: Zerk, Zirk, também no sentido de pasto), pau-a-pique (Paupick), porteira (Portehre) ${ }^{18}$, piquete ( $R G$ : Pikett), faxinal, capão, mata-burros, cancela ( $R G$ : Kanzelle), rancho ( $R$ ansch), galpão, curral (RG: Kuhral, Koral), monjolo (ES: Mascholle), safra (RG: época em que se matam os porcos para a produção da banha; v. Schmalzbauer, Schmalzernte).

Instrumentos e atividlades adotadas pelo colono:

Enxadão (RG, SP), capinar (RG, SC: kapienen, SC: kabienen, SP: kapinieren), foice (RG: Feuse e Fuchs; SC: Feuste, Feustel; ES: Fose); foiçar (RG: feusen; SC: feusten, feusteln; ES: fosen, v. também: buschen puschen); facão (RG: Fakong; SC: Fack; v. Ansteckmesser); laço (Lasso, Lass; palavra indubitàvelmente aceita aqui, como o prova o verbo seguinte, e de certo desconhecida aos imigrantes primitivos da Al.; o Dr. Bossmann acha que o têrmo foi trazido de lá); laçar (lassieren, lassen; formas desconhecidas na Al., onde se diz "mit den Lasso fangen").

$\mathrm{Na}$ Europa, o camponês usava para o transporte em geral um carro leve de quatro rodas, que, aliás, os alemães introduziram no Brasil, puxado por cavalos ou vacas e não por bois, como a carreta brasileira. Para levar produtos aos mercados ou à venda e para transportar as mercadorias adquiridas conheciam aqui outros processos, de onde provêm os seguintes vocábulos: mula (Mule), tropa (RG: Tropp, Trupp), tropeiro ( $R G$ ), cargueiro (SC, no sentido de tropeiro e de animal cargueiro), arrieiro (ES), carguejar (SC: kargern, kalgern), cangalha ( $R G$, v. Holzbock), jacá, tipiti (RG), bruaca (RG: Browacken, SC: Prowacken), aranha, carroça (Karosse, Kaross), carroceiro, carreta (Karette, Karett), guilharda (RG: Giljarde), canzil (RG: Kansille, Kantzil), 
brocha (RG: Brosch); tamoeiro (RG: Tamuere), tolda (RG: Tolde), cambão, vaqueiro.

Os animais domésticos da terra eram, em geral, os da Europa, mas aqui havia outras raças, já aclimatizadas, que os ádvenas não conheciam. Gado: serrano (RG), calombo, crioulo (Kreolo, Kriola, Kriohl), zebu, caracu. Porcos: macau, tatu (SP), canastrão. Aves: carijó ou carajó, gigante (SP), marreco (Mareck), pato (Patte, Patt, a fêmea; daí se deriva a formação completamente germanizada Patterich, o pato macho); pateiro (SC: Pattero).

$\mathrm{Na}$ casa do colono tiveram ingresso vários utensílios desconhecidos na sua pátria, tais como:

Garrafão, moringa (RG, SC), talha (Talje), marmita (RG, SC, SP: Marmite; na língua alemã, em SC e SP, é usada para designar um conjunto de vasilhas que se adaptam umas nas outras e servem para o transporte de comida), cuia (RG: Kuije), bomba ou bombilha (RG: Bomb, Pumb, Bombilje); chaleira (RG: Schalehr, a chaleira preta de ferro); chocolateira (RG: Schokolatehr, Schikolatehr), mosquiteiro, rôdo (v. Abzieher), côcho (RG: Kusch, gamela primitiva), taramela e tramela (RG).

\section{Indumentária:}

Para diversas peças de vestuário, desconhecidas na Europa, também não havia palavras equivalentes em alemão:

Capa (RG: Kappe, Kapp, masc.; no sentido gaúcho: vestuário sem mangas para proteger o cavaleiro contra a chuva e o sol); poncho (RG: Ponsch, Punsch, p1.: Pünsche; v. também Flackerponsch, Kreditponsch; conhecida também é a palavra Pelinterponsch, composta de pelintra e pon$\mathrm{cho}^{19}$ ), pala, baeta (Bajett; no sentido de fôrro de capa ou do poncho); bombachas (Bombaschen), sombreiro, guaiaca (RG: Kuaijack), picareta (RG: Pikarette, chapéu de palha duro), cartucheira (RG: Katuschehr).

\section{Enfermidades:}

Doenças novas ou desconhecidas na Europa, que às vêzes muito molestavam o imigrante e seus animais, eram: ferida brava (úlcera de Bauru), mal-da-terra (RG, v. Landeskrankheit), amarelão (SC: Marellong, daí derivaram em SC o adjetivo amarellicht), fogo selvagem (SP, pênfigo foliáceo, v. Wildfeuer); doença-de-macaco (v. Affenkrankheit); cachumba ( $R G$, causada principalmente, ao que se afirma, pelo vento frio dos pampas, o minuano), cobreiro (RG: Kobrere; dermatose que, segundo a crença dos colonos, é causada por uma cobra), tristeza (doença de animais), bicheira. 
Lavoura e criação de gado:

Já que a própria mudança do sistema econômico motivou a adoção de muitas palavras portuguêsas e indígenas, está claro que a economia agrícola e a criação de gado do luso-brasileiro haveria de contribuir em escala ainda maior para o acolhimento de estrangeirismos:

Fazenda (Fasende); Fazendeiro (Fasendehr), estância (RG: Stanz; assim chamam também um lugar perto de São Leopoldo), estancieiro ( $R G$ : Stansero), bolas ( $R G$ : no sentido de boleadeiras), invernada ( $R G, S P$ ), invernar ( $R G$ : invernieren), charqueada ( $R G$ : Scharkeade), granja (RG: Gransche), chácara (Schakra; RG e SP: Schacker), chacareiro, sítio, sitiante, rodeio, taipa, data (terreno).

Usos, costumes, tipos humanos:

Também os costumes e usos dos novos vizinhos eram forçosamente designados com as denominações estranhas:

Trovas ( $R G$ ), trovador ( $R G$ ), fandango ( $R G$ ), serra-leão ( $R G$ : quadrilha simples), samba, baião, serenata ( $R G)$, violão, batuque, cavaquinho, modinha, morena, loirinha ou loira, abraço, ó de casa! ( $R G$ ), bicho (jôgo de azar), rifa, churrasco, churrascada; fazer avenida (footing; Avenida machen); feiticeiro, feitiço, fazer uma promessa (eine Promesse machen), reza (Räse), novena, (dar um) jeito, (einen Schehto geben), jeitinho, bôlo de noiva.

Colono (SP: Kolone, Kolonist; no sentido de trabalhador rural), camarada (SP: Kamerad; trabalhador rural), agregado ( $R G$ ), peão, feitor, capataz, amigo (no sentido brasileiro), capanga, caboclo ${ }^{20}$ ( $\mathrm{Ka}$ bokler), caipira (SP), vaqueano ( $R G$ ), botocudo (Botokude), bugre (RG, SC: Buger; SC-J.: Bugger), intruso, posseiro, devoluto ( $R G$ : devolut; terra devoluta), grilo (SP: possuidor ou ocupante de terreno com título falso), grilado, usocapião (Usekapiong).

\section{Elementos urbanos: -}

O imigrante que se estabelecia nas cidades havia de constatar também muitas novidades que na Europa não conhecia: sobrado (P-C.: Sobrade), bangalô (Bungalo), vila (SP: grupo de casas com jardim comum), avenida (Rio: o mesmo que vila em SP), edifício (arranha-céu com elevador), prédio (idem; e terreno com construção na cidade), apartamento (Apartament), favela ( $R J, S P)$, maloca ( $R G)$, chalé ( $R G)$, cortiço (SP), copa, dispensa, mato (capueira, mato não cultivado, diferente do da Europa, nos bairros e arredores da cidade).

Móveis desconhecidos na Alemanha:

Pia, camiseira, cama-turca (SP), criado-mudo, esteira (SC: Stöhr, Stehre), marquesa (RG: Markés). 


\section{Profissões:}

Tintureiro, tinturaria, copeiro, copeira .

Vida politica e administrativa:

Além dos estrangeirismos que obrigatòriamente aceitavam para designar os fenômenos da natureza e sociedade brasileiras os colonos tinham que admitir grupo não menos numeroso de têrmos para dominar lingüisticamente a nova situação que encontravam na administração e na política, bem cora certos fenômenos históricos e noções geográficas. Neste terreno, o imigrante deparava também condições que não podia alterar, e sòmente em casos raros acertava ao transferir para elas uma noção européia, pois, por exemplo, o burgo-mestre alemão não correspondia, no sentido estrito da palavra, ao prefeito, a vila não era aldeia. nem cidade e assim por diante.

Município (Munizip), distrito (Distrikt), Capital, vila, sede, intendência (RG: Intendenz); prefeitura (Prefektur; Präfektur), prefeito (Prefekt, Präfekt), câmara (Kammer), câmara municipal (Munizipalkammer), interventor, governador (também: Gouverneur), praça, grupo escolar (Grupo), assistência (SP: Assistenz), coletor (Kolektor), coletoria (Kolektoria), cartório, fiscal, fiscalizar (fiskalisieren), fiscalização (Fiskalisation, Fiskalisierung), multa (Multe), multar (multieren), despachante (Despaschant), despachar (despaschieren; palavra usada, em alemão, no sentido de remeter); estampilha (Estampilje), Stampilje), paciência, procurador, tiro (tiro-de-guerra), guarda-civil, certificado militar (Zertifikat), fronteira, faixa da fronteira, coronel (como título político), salvo-conduto (Salvokondukt), santa-casa.

Medidas e dinheiro:

Braça (RG: Brasse), alqueire (SP: Alkehr), légua, palmo (Palme, Palm), medida, quarta ( $R G$ : Quart), sesmaria, quadra ( $R G$ : Quader), lote (Lotte), arroba (Arobe, Arober), vintém ( $R G$ : Wentien), pataca (Patack), patacão, mil-réis, conto, tostão, cruzeiro.

\section{História e geografia:}

Farrapos (Farrappen), mascates (Maskatten), maragatos (Maragatten; revolucionários de 1893), caudilho, gaúcho, barriga-verde, bandeirante (Banderant), mineiro, carioca, capixaba, nortista, nordestino, cabeça-chata, sertanejo, luso (no sentido de luso-brasileiro), teuto (no sentido de teuto-brasileiro, v. Deutschbrasilianer), assissita (RG: Assisist, adepto de Assis Brasil); borgista (RG: Borschist, adepto de Borges de Medeiros), getulista (Getulist, adepto de Getúlio Vargas) ${ }^{21}$. Os partidos atuais em geral são designados pelas iniciais, pronunciando-se as letras de forma portuguêsa: UDN, PTB, PSD etc. - Campanha (RG), cam- 
po (Kamp; v. Kampland; a palavra Kamp é conhecida também na Alemanha, mas para significar um terreno, campo agrícola, cercado), serra ( $R G$ ), serrano (RG: Serraner), coxilhas, litoral (SC, SP), minuano ( $R G$ ), pampeiro (vento), interior (v. Innere), sertão, terra-roxa .

Com a exposição acima pretendíamos provar que grande quantidade de palavras portuguêsas não foi aceita pelos alemães e seus descendentes por negligência ou por contágio do meio étnico luso, mas sim por necessidade material, no processo de transplantação. O ambiente lingüístico servia apenas como auxiliar, fornecendo o têrmo adequado nos muitos casos em que falhava a capacidade criadora do imigrante ou não conseguia êle dominar lingüisticamente a nova situação; entendendose por assimilação cultural uma transformação do equipamento étnico, cultural e espiritual, deve-se admitir que pràticamente tal influência não existe, o que, aliás, acontece também com muitas palavras de depauperamento. Os têrmos enumerados acima admitem sòmente uma conclusão, a de o imigrante se ter adaptado ao novo ambiente, radicando-se à nova terra e ajustando-se à nova situação político-administrativa. Naturaimente não queremos negar que na aceitação dêsses elementos linguísticos tenha havido qualquer influência secundária de ordem aculturativa, já que aos têrmos estrangeiros inere a fôrça de atrairem outras palavras, do mesmo grupo ou da mesma família; por exemplo, a palavra despachante puxa o verbo despachar (despaschieren), o têrmo laço no sentido da arma, laço na significação de nó e de armadilha, barca barqueiro, bicho bichano, lote lotear (lotieren) no sentido de dividir em lotes e lotar, ocupar todos os lugares de um veículo, de uma sala etc., ficha fichar (fischieren) etc. Aliás, a adoção dêsses vocábulos acarreta certo alheamento ante o povo de origem e o grupo étnico radicado no Brasil. Mas por outro lado também se pode dizer, sem perigo de errar, que ela enriqueceu, do mesmo modo como os neologismos, a língua alemã, assim como o idioma português se desenvolveu de modo extraordinário nesta terra nova e fecunda.

\section{Palavras de assimilação cultural}

Enquanto as palavras de acomodação são tôdas em igual grau inevitáveis, não podemos afirmar o mesmo das que foram aceitas por influência do novo ambiente lingüístico, étnico e cultural. Distinguimos dois grandes grupos, os têrmos adotados em virtude da pobreza vocabular dos imigrantes, e aquêles cuja aceitação se deu sem êsse motivo, ùnicamente por ignorância ou relaxamento, ou seja, pela imposição do novo ambiente cultural.

\section{a) Palavras de depauperamento:}

São, do ponto de vista do imigrante, tão indispensáveis como as de acomodação; consideramo-las, por isso, relativamente inevitáveis. Tal 
Inevitalibilidade relativa surge quando, em conseqüência do processo de transplantação, ou depois dêle, entram de repente no horizonte do imigrante coisas e objetos que, apesar de existirem também no país de origem, lá não desempenhavam papel algum ou sòmente secundário, de maneira que se ignoravam os respectivos conceitos e expressões, principalmente os mais especializados. Dava-se isso, por exemplo, com o cavalo, que naturalmente conheciam, mas sòmente como animal de tração, se - como camponeses pobres - não eram obrigados a empregar as vacas leiteiras no trabalho agrícola. No Brasil, o cavalo tornou-se o quase exclusivo meio de transporte pessoal e de cargas e, além disso, como cavalgaduras, tornou-se o símbolo de prestígio do colono. Os imigrantes entraram, portanto, em relação muito mais íntima com o cavalo, e em tempos passados tôda gente nas zonas coloniais andava a cavalo, homens, mulheres e crianças, moços e velhos, e isso em tôdas as circunstâncias, para ir à venda, ao moinho, à cidade, à missa, às reuniões, à escola etc. Houve quem dissesse ser o cavalo a bicicleta do colono. Interessante é notar que a influência luso-brasileira neste terreno foi maior junto aos colonos oriundos daquelas partes da Alemanha em que - cavalo era menos usado e substituído muitas vêzes pela vaca leiteira (assim, por exemplo, no Hunsrück) do que junto aos pomeranos, que conheciam melhor êste animal como cavalgadura, ainda que como propriedade de seu patrão-latifundiário. Assim se explica que quase tudo - que se refere ao cavalo seja designado com o nome português, algumas vêzes ao lado da expressão alemã. Facilitava a aceitação dêsses vocábulos o fato de o cavalo ser enviado e comprado pelo luso-brasileiro dos campos próximos, o que demonstram, principalmente, as designações do pêlo dos animais, usados ao mesmo tempo como nomes individuais: 22

Rosilho (Rosilje), baio (Bai), picaço (Pikass, Bigass), mouro, lazão ou alazão (Lasong), tobiano (Tupiano), lobuno (Lobun, Lubune), tostado, malacara (Malagar), tordilho (Tordil); zebruno, gateado, ruão ou ruano (Ruane), marchador, troteador, égua (Ägwa), matungo ( $\mathrm{Ma}$ tunke, Madunke), empacador (Packador), petiço (Petiss), mula (Mule), potranco, pangaré (Bangreh), zaino (Saïno).

Mesmo as doenças, os defeitos e os remédios são conhecidos pelos nomes portuguêses:

Garrotilho, bicho-berne (também Berne), bicheiras, broca, matabicheira, mata-carrapato, estropiado (strupiado, stropiade, strupiat), mancar (mankieren), chucro (schucker), cabeçudo (kabesude).

Da mesma forma, os arreios, quase sem exceção são designados com palavras de origem portuguêsa, o que se liga também ao fato de serem diferentes dos usados na Europa: 
Lombilho, sela, selim, serigote (Serigott), carona (Garonn); buçal; pelego (RG: Pelech, SC-Br.: Beleg); freio (Freh); relho (Relje), chicote (Schikott), mala, cabresto (RG: Kabrest, SC-Br.: Gaprest), botas, botinas (Botinnes), rédea (Redche), chilenos, rabo-de-tatu, coxinilho (Koschnil), rabicho (Rabisch), peitoral, serrilha (Sirilje); sobrecincha, badana (Badérn), cincha, travessão, barrigueira (Barrigehr), látegos.

Outras palavras ligadas ao cavalo:

Estafeta (RG: Stafette), cancha (Kansche), carreira (Karehre), andar de garupa (Garupp reiten), marcha troteada (Marschtroteade), andar de pêlo ou em pêlo (impelle reiten).

Naturalmente algumas dessas expressões eram evitáveis (também para os imigrantes das camadas inferiores), como, aliás, o prova o emprêgo paralelo de algumas designações alemãs ${ }^{23}$; o complexo do cavalo, entretanto, não era evitável, de maneira que em algumas regiões coloniais do RG usam até o pleonasmo Kawalo-Pferd (cavalo = Pferd).

Outro complexo de palavras assimilado no $\mathrm{RG}$ é o que se refere ao carro de boi e ao boi como animal de tração, veículo e animal que desde logo os colonos receberam dos luso-brasileiros:

Carreta (Karett, Karette), canzil (RG: Kansille, Kantzil), brocha (Brosch), tamoeiro (RG: Tamuere), chaveta (Schawette), tôldo (RG: Tolde), laço (RG: Lass), laçar (lassieren, lassen); tristeza (doença). - Também os nomes individuais para os bois de tração ou de puxar (v. Puschochsen), são em sua na maioria de origem portuguêsa, talvez por se terem adquirido os bois dos criadores lusos: Mimosa, Gaúcho (Gaúsch), Barroso, Malandro, Lavrado (Lavrade), Estrêla (Strela), Brasino, Pintado (Pintade) etc.

Quais eram, entretanto, os motivos para o acolhimento de tantos têrmos relativos à água, aos ribeirões, aos rios e à navegação? $\mathrm{Na}$ antiga pátria, as relações dos imigrantes com a água não parecem ter sido muito íntimas, como o demonstram as palavras seguintes; em todo caso, não haviam sido obrigados a aproveitar os rios para o transporte de seus produtos como aqui no Brasil:

Lagoa (Lagoh), banhado (SC: Panjade, RG: Banjado), açude (SC, SP), salto, reprêsa, cachoeira (Kaschoär), passo (Pass), várzea, remanso (RG: Remangse), rampa, doca, trapiche (RG: Trapisch), praia, caíque (RG: Kahick); canoa (RG: Kanoh) lancha (RG: Lansche), barca (RG: Barke), barqueiro (RG), balsa (RG: Balse), jangadas, remo (RG: Rehm), gasolina (RG: Gasoline; pequeno barco a motor); planchão, sanga.

A caça na Alemanha era privilégio do rico, que tinha de pagar um impôsto, ou do latifundiário; a pesca era um luxo ou uma profissão especializada. No Brasil ambas, na época de imigração, eram livres, e os colonos podiam caçar e pescar à vontade. Daí a introdução de muitos 
têrmos para os respectivos apetrechos que na Europa não haviam usado ou conhecido:

Picapau; trabuco (RG: Trabuck, Trambuck), cartucho (RG: Kartusch), arapuca (Arapuck), alçapão, gaiola (Gaiole), chumbo, espoleta (RG: Spolett, Spulett), fisga (Fisge), tarrafa ( $R G$ ), bodoque ( $R G$ : Bodock, Bidock; SC: Pitock), funda (RG: Funde), forquilha (para a funda ou bodoque), pelota (Pelote), espingoleta (Spingolett), pari (Baris), laço (armadilha), isca.

Outros artigos que provàvelmente só aqui no Brasil entraram no horizonte do imigrante foram: Fumo (Fumm) ${ }^{24}$, fumo-crioulo (RG: Kreolefumm) piteira, cigarrilho, carteira, cinto ou cinta, tamanco ( $\mathrm{Ta}$ manke), chinelos (Schinellen), tapetes ( $R G$ : Tapeten), alfafa ( $R G$ : Alfaf), milho ( $R G$ : Milje), Kabrittenmilje ( $R G$, milho de cabrito, i. é, híbrido), amendoim (Mendowieh), laranja ( $R G$ : Laransche, Laransch, Ransch), gira-sol, limão (ES, SP), amora (RG, ES).

Nas regiões em que se planta a cana de açúcar, os colonos se dedicam também à destilação de aguardente e álcool, conhecendo então os seguintes têrmos ligados ao processo aqui introduzido há vários séculos:

Cana (SC: Kanne, v. também Futterkanne e Salzkanne), bagaço (Bagass, Bagasse), melado (SC: Melade), melado do côcho (SC-B1.: Koschmelade), rapadura ( $\mathrm{RG}$ : Rapadur); alambique ( $\mathrm{RG}$ e $\mathrm{SC}-\mathrm{B} 1$. : Lambick, SC-J.: Nambicke), alambicar (SC-B1.: lambickieren; SCJ.: mambickieren), pipa (Pippe; medida e bartica), cachaça ( $R G$ : Kaschass), pinga, mata-bicho, puxa-puxa (RG: Puschepusche).

Grande grupo de vocábulos portuguêses provêm do progresso técnico e social que, sòmente depois da imigração, isto é, no comêço do século atual, começou a exercer influência nas colônias distantes e isoladas. Trata-se de um grupo intermediário entre os dois sub-grupos de palavras a que chamamos de assimilação. Principalmente nas colônias com progresso técnico e civilizatório a assimilação toma impulso à medida em que o conservantismo perde terreno. A adoção dos têrmos em aprêço significa que a influência da etnia dominante se vai intensificando, pois tôdas essas palavras ouviram-nas primeiro dos luso-brasileiros e ouvemnas hoje talvez diàriamente em português:

Querosene (Kerosehn), álcool, fogareiro ( $R G$, SP), gasolina (Grasolin; também barco a motor); pôsto de gasolina (Gasolinposten, tradução errada, pois Posten em alemão significa emprêgo, sentinela), fósforo (Phosphor), sorvete (Sorwett), picolé, sorveteria, frigorífico, bomba (bomba de estourar), foguete (Fogett), bicicleta (Bisiklett), bonde (Bond), malharia, usina, passeio e calçada (Kalsade, Kalsat), farelo, farelinho, chuveiro, chuveiro elétrico, vitrola, rádio-vitrola; discoteca (Diskothek); isqueiro ( $R G$ ), peça, oficina, gilete (Schilett), carro-motor ( $R G$ ); lançaperfume, maternidade (SC); palha de aço, palhinha, baliza, diligência 
(RG: Dilischenz), picareta (Pikarette, Pikarett), siderúrgica, siderúrgico (siderurgisch), metalúrgica, grampo e grampinho (P-C.), torneira, seguro, fécula ( $S C$ ), fila, bicha ( $R G$ ), sábado inglês, enceradeira, enceradeira elétrica, loção ( $R G)$, mecânica, mecânico, mangueira, matériaplástica (Plastika), faixa ( $R G$ : faixa cimentada de uma estrada), estufa ( $\mathrm{P}$-C., para aquecer a casa, Stufa), estopa, piscina, liqüidificador, batedeira elétrica, chapa, fôlha de Flandres.

O progresso técnico motiva também a adoção de muitos têrmos de materiais de construção, os quais o imigrante novo, lidando com operários que não falem o alemão, aceita com facilidade, pois na maioria dos casos nunca construiu casa no país de origem:

Fôrro, caibro, viga, barrote, ripa, ladrilho, calha, encanador, raspador, manilha, água-furtada, fossa, ralo, telha, telhado, bóia, pau-a-pique.

Complexo típico de vocábulos adotados em conexão com o progresso técnico refere-se ao automóvel, que sòmente após a primeira guerra mundial conseguiu penetrar nas colônias e que até o imigrante mais recente na Europa então não possuía:

Caminhão, perua, baratinha, barata, microônibus (Mikroonibus), pau-de-arara, pneu, câmara (de ar), camisa, jardineira (SP), ubá (= jardineira, ES), gostosão ( $R G$ ); auto de praça (Prassa-Auto), para-lama, para-choque, óleo mineral (Mineralöl), gasolina (Gasolin; na Al.: Benzin), manivela, buzina, buzinar (businieren), embalar (engballieren), lacrar (lakrieren), marcha à ré, encostar (engkostieren), travar, (trawieren, eine Trawada geben), acelerar (assellerieren), borboleta (roda de contagem dos passageiros no ônibus), radiador, carbonizador, distribuidor etc., etc. - $E^{\prime}$ interessante verificar que certas palavras de significação geral em português são usadas sòmente em sentido restrito, como aqui a respeito do automóvel: câmara, camisa, acelerar, encostar etc.

Observamos também que têrmos técnicos, conhecidos pelos alunos na escola, fàcilmente se difundem nas famílias alemãs ou de origem alemã, mesmo de nível cultural elevado:

Tabuada, problema, mapa (Mappe), matemática, ginástica, geografia, histórie, boletim, média (do boletim), ginásio, colégio, 1a. e 2a. séries, científico, clássico etc.

Até na agricultura, ramo econômico mais conservativo, são usadas diversas expressões que demonstram o progresso. Em Santa Cruz, RG, mas também em outras zonas onde se planta o tabaco, dizem estufa (de tabaco) (Stufa), estufar (stufen); vocábulos que refletem algum progresso técnico são também: carrapaticida, inseticida ( $R G$ : Insektisid), tortade-algodão, farelo, farelinho, quirera.

Outro complexo de palavras incorporadas ao idioma alemão se refere ao futebol, esporte nacional que, vindo das cidades, penetrou aos poucos nas colônias teutas: 
Turma, torneio, jôgo, trava, golo, goleiro, bola, calção, chuteira, campo (Kamp), campeão, juiz, chutar (schutern) etc.

Como palavras de depauperamento podem ser consideradas também muitas expressões usadas nas relações com as autoridades, tais como:

Requerimento (RG: Reklement, Reklament, Rekrement), sisa, estampilha, sêlo, selar, selieren), selagem (Selierung), selagem do estoque (Stockselierung), taxa etc.

Cabem aqui tôdas as designações geralmente conhecidas e usadas apenas pelos especialistas de certos ramos de atividade humana, por exemplo os nomes dos diversos tipos de fazenda: chita, riscado, riscadinho, mescla, morim, brim etc.

Com a penetração das palavras de depauperamento, relativamente dispensáveis, começa indubitàvelmente o processo de assimilação, pois com elas já entram certas idéias e noções do meio ètnicamente diverso. O esporte típico alemão, a ginástica, é suplantado pelo futebol. O complexo de têrmos relativos ao cavalo revela que o teuto adotou certos usos e costumes do ambiente luso. Mas, apesar de tudo, o meio lingiíistico ainda não desempenha papel saliente; não raro, as palavras são tão germanizadas que ninguém se lembra mais da sua origem portuguêsa: Kanne, Fumm, Freh, Barke, Rehm, lassen, stufen, schucker etc.

\section{b) Palavras de assimilação cultural pròpriamente ditas}

Neste grande grupo mencionamos tôdas as palavras para cuja adoção não encontramos outro motivo senão o relaxamento ou seja a deficiência de conhecimento vocabular. Não havia necessidade absoluta nem relativa de aceitá-las, de vez que o alemão possui têrmos que as substituem perfeitamente. Aqui já não é mais o objeto ou a coisa que se impõe, mas o ambiente étnico, cultural e espiritual; é exclusivamente a convivência num meio de língua diferente que explica a aceitação. Devem, portanto, ser consideradas como o verdadeiro índice do processo de aculturação em marcha. Se afirmamos que são absolutamente dispensáveis, isto não significa, é claro, que todos os indivíduos fôssem tão instruídos que as poderiam ter evitado, mas sim que de um ponto de vista geral não vemos motivo material ou pobreza na língua alemã que obrigasse os imigrantes e seus descendentes a aceitá-las. Por outro lado, a insuficiência lingüística subjetiva por si só não basta como explicação. Os motivos eram vários e, não raro, mais do que um só. Podem ser encontrados, por exemplo, em certas deficiências reais do vocabulário alemãa, na pressão das autoridades, na pressão moral do ambiente, na preferência pela voz estranha, na vaidade pessoal etc., como num depauperamento lingüístico que se processou depois da imigração e no domínio cada vez mais limitado do idioma tradicional, que afinal acaba restrito ao uso doméstico e familiar. O conhecimento imperfeito do 
alemão se reflete em formações como "fábrica de manteiga" (Butterfabrik em vez de Molkerei), "fábrica de cerveja" (Bierfabrik em vez de Brauerei), "fábrica de vinho" (Weinfabrik em vez de Kellerei), como, por exemplo, pelo emprêgo de "rabo" (Schwanz) em lugar de "germen" (Keim).

E' significativa a suplantação sistemática, na língua alemã, tal qual é falada na Europa, de vocábulos estrangeiros por palavras portuguêsas, quer se trate de estrangeirismos de origem francesa, quer de origem inglêsa, latina ou outra qualquer. Naturalmente a posição dêsses estrangeirismos no idioma alemão é sempre um tanto fraca, sobretudo no vocabulário de indivíduos pertencentes às camadas sociais inferiores, de onde proveio a grande massa dos imigrantes alemães e que não estudaram na escola outra língua senão a do próprio país. Compreende-se que as palavras de orig€m estrangeira não tenham a firmeza ou resistência dos têrmos pròpriamente alemães. A sua evolução no vocabulário da língua alemã, tal qual é falada no Brasil, até hoje não foi estudada, apesar de seu indiscutivel interêsse. Distinguimos três grupos:

1) Palavras estrangeiras, outrora de uso geral na Al., mais tarde, porém, substituídas, em conseqüência do movimento de depuração lingüística, por palavras genuìnamente alemãs, e que aqui subsistem ou foram reavivadas por influência do português. Alguns exemplos:

Rádio (o aparelho de recepção; na Al., Empfänger, Empfangsgerät), estação de rádio (Radiostation; na Al.: Rundfunksender, Sender), novela de rádio (Radionovelle; Hörspiel), telefone (Telefon; Fernprecher), viaduto (Viadukt; Überführung), bazar (Basar; Kaufhaus), redator (Redakteur: Schriftleiter), advogado (Advokat, RG: Afkat; Rechtsanwalt), decreto (Dekret; Verordung), decretar (dekretieren; verordnen), licença (Lizenz; behördliche Erlaubnis), vagão (Waggon; Eisenbahnwagen), macadamizar (makadamisieren; beschottern), bilhete (Billett; Karte, Eintrittskarte, Fahrkarte), instalação (Installation; Legen ou Einrichten), instalar (installieren; etwas einrichten, legen), registrar (registrieren; einschreiben, confiscação (Konfiszierung, aqui também na forma irregular Konfiskation; Beschlagnahmung), confiscar (konfiszieren; beschlagnahmen), sanduiche (Sandwich; belegtes Brot ou Brötchen), injeção (Injektion; Einspritzung, Spritze), projeto (Projekt; Entwurf, Plan), avisar (avisieren; benachrichtigen), informar (informieren; sich über etwas unterrichten), pensão (Pension; Ruhegehalt), estação (Station; Bahnhof, Haltestelle), convir (konvenieren; angebracht sein, passen), ter pressa (pressieren; eilig sein, es eilig haben); hospital (Hospital; Krankenhaus); conversar (Konversieren; sich unterhalten, erzählen), memorando( $\mathrm{Me}$ morandum; Erinnerungsschreiben), ping-pong (Ping-pong; Tischtennis), expresso (Express, por ex.; Expressbrief, em vez de Eilbrief), consultar 
(konsultieren; befragen), competente (kompetent; zuständig), incomodar (inkommodieren; belästigen, stören, aqui até se usa a palavra desconhecida na Al.: Inkommodation; Störung, Belästigung), insistir (insistieren; auf etwas bestehen, drängen), sócio (Sozio, Sozius; Teilhaber), caçarola (RG: Kascheroll, Kasserolle; Schmortopf), pijama (Pyjama; Schlafanzug), distância (Distanz; Entfernung), naturalizar (naturalisieren, o colono no RG diz muitas vêzes "neutralisieren", neutralizar; einbürgern), naturalização (Naturalisation; Einbürgerung), cartão (Karton; Visiten-, Besuchskarte, Karte e Pappe), mina (Mine; Erzlager, Kohlenlager etc.), restaurante (Restaurant; Gastwirtschaft), emancipar (emanzipieren; selbständig werden), emancipação (Emanzipation; Erlangung der Selbständigkeit, einer eigenen Verwaltung), avisar (avisieren; benachrichtigen), aviso (aviso, Avis, Nachricht, Benachrichtigung), provocar (provozieren, RG: prowocken; herausfordern), petróleo (Petroleum; Erdöl).

2) Palavras estrangeiras em alemão que sob a influência do português tomarem sentido diferente no Brasil:

Particular (particular, partikulär ( $R G$ ), na Al.: pertencente a uma parte, especial; no Brasil só privado, pessoal), vitrina (Vitrine; na Al.: armário com vidraças; cristaleira), balcão (Balkon; na Al.: sacada de uma casa de mais de um andar), vila (Vila; na Al.: palacete), arranjar (arrangieren; na Al.: organizar), marmelada (Marmelade; na Al.: qualquer doce para passar no pão), dentista (Dentist; na Al. só prático de odontologia), cigarro (Zigarre; na A1.: charuto), nacionalidade (Nationalität, bém: Suschestion; na Al. só: influência psicológica), clube (Klub, na Al.: só pessoa entendida em técnica), concurso (Konkurs; na Al.: bancarrota, falência), sindicato (Syndikat; na Al.: organização de diversas emprêsas com uma central de venda), estudar (studieren; na Al. de preferência do acadêmico), estudante (Student; na Al. de preferência na universidade), colégio (Kolleg; na Al.: preleção de catedrático na universidade), sócio (Sozius; na Al. só de uma emprêsa comercial ou industrial), transferir (transferieren; na Al. só enviar ou trocar), nacional (national, na Al. só referente a nação, no Br.: interno), cerimônia (Zeremonie; na A1.: formalidade, no Br.: afectação), sugestão (Suggestion, aqui também: Suschestion; na Al. só: influência psicológica), clube (Klub, na Al.: sociedade exclusivista), lançar (lancieren; jogar uma novidade no mercado), título, Titel; na Al.: tratamento etc., mas não: documento), álcool (Alkohol, aqui também no sentido alemão de Spiritus, álcool para queimar), bar (Bar, na Al.: boite), talão (Talon, na Al.: canhoto nas ações para receber os juros), compromisso (Kompromiss, na Al.: acôrdo; aqui também: obrigação, promessa), audiência (SC e P: Audienz, na Al. só: recepção por uma autoridade destacada), mapa (Mappe; em vez de (geographische) Karte), matinê (Matinée; na Al. só: representação no período da manhã). 
3) Estrangeirismos de origem francesa, inglêsa ou de outra procedência no Brasil são substituídas fàcilmente por palavras de origem portuguêsa ou por formações portuguêsas, enquanto na Alemanha cederam muitas vêzes o lugar a formas genuìnamente alemãs:

Petiço (RG: Petiss, no sentido de cavalo-petiço; em SC também petiço-Pferd, na Al.: Pony), laranja (RG: Laransch; Al.: Orange, Apfelsine), farmácia (Al.: Apotheke), privada (A1.: Klosett, Lokus, Toilette); calçada e passeio (Al.: Trottoir, Gehsteig, Bürgersteig), charuto (Scharute; Al.: Zigarre), bala (Al.: Bonbon), bolacha e biscoito (Bolasche; A1.: Keks), até-logo ('Teloge; Al.: Adieu; Aufwiedersehn), nenê (no RG. também o diminutivo Nenêche; Al.: Baby, Säugling, Kleinkind), namo$\operatorname{rar}$ (RG: namorieren; Al.: pussieren), primo (Al.: Cousin, Vetter), prima (Al.: Cousine, Base), veneziana (A1.: Jalousie), camarote (A1.: Kabine), cristaleira (A1.: Vitrine, Glasschrank, Kristallschrank), maleita (A1.: Malaria), sócio (A1.: Sozius, Kompagnon; Teilhaber), tabelião (A1.: Notar); consulta (Konsulte; Al.: Konsultation; Sprechstunde), temporada (Al.: Saison; Spielzeit), palhaço (Al.: Clown, Bajazzo), fichário (A1.: Kartothek, Kartei), ficha (Al.: Karteizettel), gravata (A1.: Krawatte, Schlips; Selbstbinder), atacado (Al.: en gros, im Grossen), atacadista (Atakadist; Al.: Grossist, Grosshändler), varejo (Al.: en detail, im Kleinen), varejista (Wareschist, Al.: Detailist, Kleinhändler), terreno (A1.: Terrain; Grundstück), vício (A1.: Passion; Leidenschaft), fantasia e fantasiar-se (Fantasie e sich fantasieren; A1.: Maskerade, Verkleidung; maskieren, verkleiden), procuração (Prokuration, Al.: Prokura), tanque (Tank, Al.: Bassin, Wasserbehälter), roda e turma (A1.: Clique, Klüngel), empreitada (RG: Pretada; Al.: Akkord), empreiteiro (RG: Pretero; Akkordarbeiter), vira-lata (A1.: Promenadenmischung), encanador (A1.: Installateur Klempner), envelope (RG: Engwelop; A1.: Couvert, Briefumschlag), cinema (Zinema; Al.: Kino, Lichtspielhaus), barbeiro (Al.: Barbier, Friseur; Haarschneider), companheira (A1.: Konkubine), querosene (RG: Kerosen, A1.: Petroleum, Erdö1), Galinheiro (no teatro; Al.: Gallerie), concreto (armado) (Konkret; Al.: Beton), mochila (RG: Muschill; Al.: Tornister, Ranzen), remédio (Remedium; A1.: Arznei), barracão (A1.: Baracke), paiol (A1.: Silo), adeus (Al.: Adieu, Aufwiedersehn), novena (Al.: Novene), viva (A1.: vivat! Er lebe hoch!), namorar e tirar linhas (namorieren e Linja-ziehen no $\mathrm{RG}$, linjern em SC-J.: Al.: poussieren, flirten), marmiteiro (Al.: Proletarier, Fabrikarbeiter), marquesa (RG: Markés, Al.: Kanapée), abacaxi (Backaschie; Al.: Ananas), alfafa (A1.: Luzerne), coragem (RG: Korasch; Al.: courage). Em outros vocábulos a pronúncia é influenciada pelo português: ônibus (Al.: Omnibus); turismo (Tourismus; Al.: Touristik), aperitivo (A1.: Aperitif), caramelo (Al.: Karamelle) ${ }^{25}$, aplicar (RG: aplikieren, Al.: applizieren); orçaınento (A1.: Budget; Haushaltsplan). 
Como observamos, os estrangeirismos constituem "pontos fracos" de uma língua, pois fàcilmente cedem lugar a palavras do idioma predominante. Além dêles, tôda língua possui deficiências que constituem outras tantas pontes para a invasão vocabular. Assim, por exemplo, quando não existe designação ou quando não há uma única palavra precisa para determinada coisa ou objeto. Os alemães das várias regiões, falando dialetos diferentes, não raro usam nomes diversos para a mesma coisa. Ademais, o alemão em muitos casos, possui para uma coisa e as sílas diferenciações sòmente uma palavra genérica, enquanto que o português faz a distinção com auxílio de diversas denominações precisas (por ex.: canoa e caíque, salsicha e lingüiça). Elementos que entraram no linguajar alemão por êsse motivo ou motivo semelhante são:

Doces (RG: Doss, Dosses; Al.: Kleingebäck, Süssgebäck etc.), rôsca (RG: Roske; Al.: Kringel, Ringelzwieback, etc.), bala (RG: Balle; Al.: Gutsel, Bonbon, Zuckerware, Zuckerstein, etc.), lata (Latte; A1.: Blechkübel, Kanister, Dose, etc.); frango (junger, schlachtreifer Hahn), franga e franguinha (junges, schlachtreifes oder legereifes Huhn), palpite (Palpitt; Al.: Tip, Fingerzeig, Hirlweis), encrenca (Engkrenke; A1.: Reiberei, Schererei, heikle Lage, Ärger, Missverständnis); encrencar (engkrenkieren); emplacar (engplakieren; Al.: mit einem Nummernschild versehen); bicho (Bisch; não existe vocábulo alemão que substitua esta palavra portuguêsa de sentido amplo e múltiplo); bichoso ou bichado (RG: bischig; SC-Bl.: bischade), bicheira, empório (Lebensmittelhandlung); cacho (RG: Kasch, Kasche; SC: Käsch; na língua popular alemã uva, Weintraube, e cacho, Traube, estão em relação muito intima, de maneira que difìcilmente o imigrante alemão chamaria Traube ao cacho de banana), sesteada (Mittagsruhe, Mittagspause), pistolão (RG), plantar, alpiste, cachorro-quente (Brötchen mit Wienerwürstchen), recado, várzea, farra, fandango (no sentido de farra), marcha, broca, curativo, jóia (entrada para uma sociedade), bandeja (RG: Bandesch), bueiro (RG: Buere), gripado, bico (pequeno ganho suplementar), biscate, pipi, fazer pipi ou xixi, jornaleiro, lotar (lotieren), lotação (auto ou táxi lotado), tabelar (tabellieren), guisado, bichão, graúdo, manda-chuva, velhaco (RG: Wäljack), almofadinha (RG), pau-a-pique (RG: Paupik), cêrco, pitoco (Pitock), vacalhada (Wakaljade), galinha (homem covarde), arrebanhar ( $R G$ : arebanjieren, rebanschieren), alfabetizar (alphabetisieren), alfabetização (Alphabetisierung).

Outro grupo de vocábulos, em grande parte evitáveis, e aceitos pelos imigrantes e seus descendentes apesar de existirem sinônimos alemães, são os que se referem à política, à administração e ao Estado; a sua aceitação reflete certa pressão moral e, às vêzes, política: ${ }^{26}$

Brasileiro nato, brasileiro naturalizado, modêlo 19 , carteira de identidade, partido, deputado, vereador, procurador, advogado ( $R G$, na zona 
colonial: Afgad), licença (Lizenz), escrivão, certidão, tabelião, edital, decreto (Dekret), sisa, portaria, delegado (de polícia, RG: Delegat), grilo (SP), investigador, inspetor, cadeia ( $R G$ : Kadeh), penitenciária, legalizar (legalisieren), prêso, chapa (de carro e de eleição: Schappe), placa, emplacar (engplakieren), impôsto, alfândega, escritura (Skritura, RG: Skritur), quartel, voluntário, sargento, capitão, coronel, caderneta militar, certificado (Zertifikat), procuração, procurador, govêrno, requerimento (Rekeriment), requerer (requirieren), funcionário (público).

Muitas vêzes constatamos que indivíduos de língua alemã, mesmo os que dominam mal o português, intercalam em sua conversa elementos portuguêses que significam injúrias, insultos, maldições, exclamações de impaciência, de admiração, de espanto etc. Parece que o idioma alemão cultivado é pobre em expressões dessa ordem, pois para amaldiçoar, insultar etc. o alemão prefere em geral têrmos de seu dialeto. Outro motivo da aceitação daquêles têrmos pode ser a vaidade pessoal, o desejo de se fazer interessante, podendo também contribuir o fato de expressões estrangeiras, afinal de contas, ficarem mais alheias à personalidade, criando ou mantendo assim quase que uma distância entre quem fala e os palavrões que pronuncia:

F... de uma p... (RG: Filjaputt), p...m..., p... que te pariu, vá à m..., puxa, puxa diabo (Puterdiasch!), puxa vida, desgraçado, desgranido, diabo, caramba ( $R G$ também: Karambo), porcaria ( $R G$ : também: porcalhada), barbaridade ( $R G$ : Barridade), Nossa!, Minha Nossa!, Nossa Senhora!, Credo!, Vá plantar batatas!, Cada!

Como palavras de presunção usam entre outras: Pronto, acabou-se (RG: kaboss), formidável, cuidado, coitado, coitadinha, engraçado, engraçadinho, mais ou menos, vamos ( $R G$ : vomme!; P-C.: vomo!), viu, pois bem, pois é, boa tarde, bom dia, boa noite, até manhã (Tämanjang), até logo (Täloge, Adeloge), até já (Täschá), tchao (SP), graças a Deus, não diga, o que!, ué, uê, cala a bôca, à vontade, sirva-se, sim, não, então, pois não, pois então, muito bem, apoiado, não apoiado, bom, fora, fôrça!, viva!, entra na carreira! ( $R G$ ), está bom, está bem, tudo azul.

Aqui, parece, devemos intercalar também diversas vozes para chamar ou animar os animais:

Chó (RG: Schoh); toque! (tocke ou tock, ref. ao cão), isca ( $R G$ : iske, ref. ao cão), caminhe (Kaminje! para os bois no carro), puxa! (ref. aos bois) - e os nomes dados aos cachorros: Valente, Leão, Atrevido.

Fator de assimilação cultural, nas colônias como nas cidades, é o comércio, pois enquanto nas famílias se usa o alemão, nas lojas e vendas se prefere o português. Também nas cidades os imigrantes, principalmente as donas de casa, depois de alugarem a sua morada, têm o seu primeiro contacto com o novo ambiente no armazém, na feira e na loja: 
Loja, armazém, venda, molhadista, bazar, feira, mercado (RG: Markad), caixeiro (RG: Kaischehr), patrão, leitaria, quitanda, padaria, ( $R G)$, picador ( $R G$ ), cobrar (kobrieren), cobrança, cobrador, balcão, recibo, trôco (RG: Trock), trocar (trocken), remessa (Remesse), duplicata (Duplikat), sócio, freguês, freguesa, freguesia, carimbo, cárimbar (karimbieren), ficha, fichar (fischieren), pechincha, abacaxi (coisa difícil de vender), movimento (Mowiment), almoxarifado, almoxarifeiro (Almoscharif), armarinho, empório, fazenda (Fazende), loja de fazenda (RG: Fazendenloje), atender (atendieren), barbante (RG: Barbant), caderneta ( $R G$ : Kadernett, Katinett, livrinho em que se anotam as compras para pagamento mensal), à vista, a prazo (RG: auf Prase), a prestação (auf Prestasong), jôgo (= série de artigos).

E' difícil explicar a aceitação de uns tantos nomes relativos ao médico, aos remédios e às doenças; parece que foram acolhidos pelos mesmos motivos que as palavras usadas no intercâmbio comercial, ou por não falar o médico o alemão:

Nemedic, puigante, fortificante, xarope ( $R G$ : Scharopp), curativo, curandeiro, sarampo etc.

Nas cidades são muito usados os seguintes vocábulos que se referem às condições de habitação e às relações com os empregados domésticos, setor em que não raro ocorrem os primeiros contactos com a população de língua portuguêsa:

Fiador, zelador, copeira, arrumadeira, empregada, criada, patrôa.

Além das palavras até aqui enumeradas notam-se muitos têrmos de origem portuguêsa para cujo acolhimento não encontramos explicação além da comodidade e da influência de novo ambiente. Tais são, por exemplo, as designações de parentesco, que Emílio Willems quer explicar pela aceitação do padrão familial luso-brasileiro:

Mamãe (Mamai), papai ou pai (RG: Babai, Balbai; SC e P-C.: Pai), avô (Wowoh), avó (Wowoh), sobrinho, sobrinha, cunhado, cunhada, compadre (Kompader), comadre (Komader, RG: Kommadersch), madrinha, padrinho, tio, titia ou tia, parente (SC-J.), primo (Prime), prima, primo segundo (Segunde-Prime), primo terceiro (Tersere-Prime), compadresco (usam a formação híbrida: Kompaderschaft) e comadresco (Kommaderschaft).

Outrossim, para grande número de palavras avulsas não encontramos explicação satisfatória além da comodidade lingüística, a pronúncia mais fácil da palavra portuguêsa, por ser mais breve ou talvez mais acertada ou exata, ou o pouco uso da palavra alemã e, em alguns casos, a consonância com palavras alemãs:

Chupar (RG: schuppen, SC-J.: schuppern, laranja, cana etc.), chupeta, baixada, banhado, escoteiro, machucar (maschukieren), amolar (amolieren), amolação, cachimbo, puxar (puschen, v. Puschochse), galinhada 
(RG), canja, cêrca (RG, P-C.: Zerk; SC Zirk), cercar (einzerken, einzirken), caneca ( $R G$ : Kanecker), cadela, rio ( $R G$ : fem.), ribeirão, córrego (SP), leitão, cabrito ( $R G$ : Kabritt, v. Kabrittenmais), sanga, espigão, (SP: Spigong), revista, valor ( $R G$ ), boletim (periódico), pasta (Paste), refugo, refugar (refugieren), boné ( $R G)$, bigode, cavanhaque, gastar (SP, P-C): gastieren, vergastieren), ida e volta, volta, voltinha, arrumar (RG: rumieren), subida, descida, despachar (despaschieren), valeta, chegar (schegen, no sentido de bastar), trabalhar (RG: trabellen), sôco, ponta-pé, surra, quadril, coalhada, cacete ( $R G$ : Kassett), canivete ( $R G$ : Kaniwett), caneta, profissão ( $R G$ : Profission), profissional ( $R G$ : Profissionist), tocar ( $R G$ : tocken), trepar (SC-Br.: treppen), convidar ( $\mathrm{SC}-\mathrm{Br}$.: konviden), surprêsa ( $\mathrm{RG}$ : na ante-véspera das bodas, v. Surprêsa-Leute), safra (RG: dos porcos), safrista ( $\mathrm{P}$ : colono cuja principal renda provêm do cevado), gamela (SC: Kamelle), fogueira, fio (arame e linha), lixo e cisco (interessante é a formação Lischolatte e Ziskolatte, lata para lixo ou cisco), encruzilhada, estrada, amolar (amollieren), amolação, suspensórios, pousar (SC$\mathrm{J}$ : posen), suplente, balde, carão ( $\mathrm{RG}$ : recusa de uma dança por parte da moça), orçamento (Orsament), enfermeiro, enfermeira, recreio, passeio (em três sentidos: 1. calçada, 2. jardim para passear ( $P-C), 3$. ato de passear), bola, raiva (também: doença), passa-tempo, batido ( $\mathrm{P}-\mathrm{C}$ : no sentido de gasto), cachinho (de cabelo), cartucho ( $\mathrm{P}$ C.: saquinho de papel), piscar (piskern, no sentido de namorar), descobrir (P-C.: deskobrieren), espinho (RG: Spinche, Spinje, P-C.: Spinjo, de plantas e também no sentido dificuldade), espinha ( $\mathrm{P}-\mathrm{C}$.: Spinje, da pele), porco (SC), gatuno, ladrão ( $\mathrm{SC}$ ), criação, balaio ( $\mathrm{SC}$ : Balaie, Balaije), bôbo (SC), brigar (SP, RG: briegen), briga ( $R G$ : Briege), mexer (RG: meschen), pinto (SP), novilha, pista, passe (SP: Pass, da CMTC), mudança (SC), vaca (SC: Wacke), mola, machucar (maschukieren), distintivo, muda, verdureiro, verdureira, rendimento ( $R G$ : Rendiment), conversa ( $R G$ : Konvers), conversar ( $R G$ : konversen), leilão, leitão, gaita, gaiteiro, maço, cancha ( $\mathrm{SC}$, para bolão), bolão (RG, SC), pastor alemão (SP: Paster, Pastor, deutscher Pastor: raça canina), bombeiro (Bombier), pau (vulgarmente também: membro viril), trago ( $R G$ ), companheiro, companheira, chapéu ( $R G$ : também o pleonasmo: chapéu-Hut), botinas ( $R G$ ), picareta ( $R G$ : Pikarett), pa(Posade machen), barranca (Barrancke), moço, moça, parreiral (RG), lito, moleque (Muleck), guri ( $R G$ ), guria ( $R G$ ), pousada, fazer pousada namorado, namorada, foco (P-C.: lâmpada elétrica), posar (posieren), limão (SP, ES), amora ( $R G, E S$ ), frios, besouro, condução, ressaca ( $R G$ Laj.), associação, laço (de uma fita), peru, portão, machado, rapar (RG: rapen, também no sentido de fugir), espanhol (Spanjol), cabo (de feria- 
menta), cautela, estrago (RG: Estrage), frieira (RG: Friëre), ferrão (dos insetos), prumo, traça (Trasse), enxó, pião, mala (Male).

Na língua vulgar dos alemães e seus descendentes no Brasil encontram-se também algumas frases idiomáticas portuguêsas para cuja aceitação não vemos motivo:

Fazer questão (Quästion machen), ficar com alg. c. (mit etwas bleiben), fazer anos (Jahre machen), esperar alguém (jemand warten), fazer fita (Fitta machen), tem (es hat), lotes de frente (Lotten mit Front), sala de frente (Frontsaal), ser frouxo (froscho sein), ser mole, (molle sein), ser macho (RG: masch sein), ser suspeito (suspeito sein), ser pão-duro (em SC-Rio do Sul existe uma "Pão-duro-Strasse", rua dos pão-duros), ser sem-vergonha (RG: seng Vergonja sein); fazer prosa (Prose machen, prosen), fazer uma banana ( $R G$ : eine Banane machen); ter prá chuchu.

Foi o nosso intuito mostrar, formando grupos ou complexos de palavras, como o imigrante se viu obrigado a aceitar muitas designações para acomodar-se ao novo ambiente, seja por motivos objetivos ou subjetivos, e ainda como, pela insuficiência de seus conhecimentos lingüísticos ou por dificuldades inerentes ao próprio alemão, êste foi, invadido por palavras evitáveis, ou seja, de assimilação cultural, já se tornando difícil ajuntar êsses vocábulos em grupos. Tentamos descobrir sempre os motivos de sua aceitação, que em certos casos eram vários a um tempo, levando-nos a inserir o mesmo vocábulo em grupos diferentes. Para os casos em que não achamos motivo algum, registamos o têrmo entre as palavras avulsas de assimilação. Não significa isto que não tenha havido motivo para a aceitação de tais elementos; estamos até convecidos que em muitos casos êle existe, o que prova o fato de encontrarmos o mesmo têrmo em tôdas as regiões do país e até em colônias isoladas, como, por exemplo, a palavra caneca (Kanecker). Uma prova que confirma nossa opinião de que em geral existem certas razões para o acolhimento dos vocábulos, encontramo-la na pesquisa do Prof. Egon Schaden, trabalho que só conhecemos depois de encerrar a nossa investigação. Refere-se o Prof. Schaden a uma pequena colônia isolada que até a época da pesquisa não mantivera relações com outras comunidades; o interessante é que quase tôdas as palavras mencionadas por êle já as tínhamos encontrado alhures; sòmente poucas delas não se acham em nossa relação, o que, aliás, não quer dizer que sejam ignoradas em outras regiões.

O prof. Emílio Willems, em seu livro $A$ aculturação dos alemães no Brasil, somou os têrmos portuguêses existentes no linguajar alemão do Brasil, distribuindo-os segundo porcentagens em diversas classes (págs. 300 e segs.). Não achamos que tal procedimento possa explicar qualquer coisa relativa ao estado de assimilação cultural, e isso pelos seguintes motivos: $10^{\circ}$ As palavras enunciadas não são conhecidas por todos os que 
falam a língua alemã; ao contrário, cada indivíduo ou cada grupo, cada colônia, por exemplo, ou certa camada social ou profissional, sòmente usa e conhece pequena parte dêsse vocabulário. Os alemães e seus descendentes não formam um grupo étnico compacto, pois estão distribuídos por um vasto território, não havendo relações entre as respectivas colônias e os respectivos grupos no país, o que prova o fato de êles utilizarem para designar a mesma coisa nomes diferentes, conforme o ambiente luso em que vivem. Assim, por exemplo, o colono em SC diz Past ou Bast (pasto), expressão desconhecida no RG, onde se fala em Portrehr (portreiro). $20^{\circ}$ Há muitos vocábulos que são usados simultâneamente, e talvez raras vêzes, com as respectivas palavras alemãs ou dando-se preferência a uma ou outra, conforme as circunstâncias ou o gôsto individual. $3 .^{\circ} \mathrm{O}$ vocabulário flutua e está sujeito contìnuamente a alterações. $4 .^{\circ} \mathrm{O}$ valor assimilativo dos diversos grupos e sub-grupos de vocábulos é bem diferente, e enquanto as palavras de acomodação são pràticamente assimiladas pela língua alemã, as de assimilação cultural contribuem para a integração do imigrante e de seus descendentes num meio cultural diverso. Vocábulos de valor assimilativo tão diferente não podem ser simplesmente somadas no intuito de se demonstrar algo relativo ao processo de aculturação. $50^{\circ} \mathrm{O}$ número de elementos portuguêses em si nada significa quanto ao estado de assimilação do indivíduo; conhecemos pessoas que empregam numerosos lusismos na língua alemã, sem, entretanto, sentirem qualquer apêgo à nossa terra ou à nossa gente. Sendo assim, devese tomar a precaução de não ajuizar do estado de assimilação sòmente à base da quantidade de palavras portuguêsas. Maior acêrto é possível quando se consideram principalmente os lusismos dispensáveis que a pessoa usa. Devia-se, portanto, procedendo-se de acôrdo com o Professor Willems, distinguir nitidamente entre as palavras de acomodação e as de assimilação pròpriamente ditas. Aliás, o modo de falar, a construção das frases, os gestos etc. são muito mais significativos do estado de aculturação de um indivíduo do que o número de palavras portuguêsas que por ventura empregue.

A assimilação não é apenas um processo lingüístico, mas um processo "total", que afeta todos os aspectos da personalidade: modifica não sòmente o seu modo de falar, como a sua maneira de pensar, de agir e de viver. A aculturação, afinal de contas, consiste na passagem de uma etnia para outra, resistindo a êste processo, que se estende por gerações, apenas alguns traços secundários. Por isso mesmo reconhecemos também que a relação dos vocábulos por nós apresentada, apesar do interêsse que possa ter, não permite senão conclusões muito gerais acêrca da aculturação do grupo étnico alemão. Para tal, deveria proceder-se a pesquisas locais, limitadas a uma colônia, como o fêz o Prof. Schaden, a determinado grupo ou, ainda, a uma camada social. 


\section{FONTES BIBLIOGRÁFICAS}

Bossmann, Reinhold: "Zur deutschbrasilianischen Mischsprache", Deutsche Nachrichten, São Paulo, 5, 6 e 12 de março de 1954.

Campos, Custódio F. de: "Falares Blumenauenses", em: Centenário de Blumenau, 1850 - 2 de setembro - 1950, edição da Comissão de Festejos, págs. 373 e segs.

Furrer, Albert: "Deutschbrasilianisches Brauchtum", Serra-Post-Kalender, 1939, págs. 89 e segs.

Oberacker, H.: Vocabulário de palavras portuguêsas que os descendentes de colonos alemães acolheram na lingua vulgar, em: Sociologia, vol. $1 .^{\circ}$, n. ${ }^{\circ} 3$, de 1939 . V. nota 1 .

Oberacker, Karl Heinrich Jr.: Neuschöpfungen der deutschen Sprache in Brasilien, em: Staden-Jahrbuch, tomo 5., págs. 175 e segs. São Paulo, 1957.

Schaden, Egon: "Aculturação lingüística numa comunidade rural", Jornal de Filologia, vol. I, n. ${ }^{\circ}$ 1, Julho-Set. 1953, São Paulo.

\section{NOTAS}

(1) Muitas das palavras enumeradas aqui já foram mencionadas num artigo do autor publicado na revista Sociologia (vol. $1 .^{\circ},{ }^{\circ}{ }^{\circ} 3$, de 1939 ) sob o título "Vocabulário de palavras portuguêsas que os descendentes de colonos alemães acolheram na sua língua vulgar". Essa relação, aliás, foi transcrita, um tanto ampliada, por Emílio Willems em seu livro Assimilação e Populações Marginais no Brasil (Cia. Editôra Nacional, São Paul,o 1940, págs. 191 e segs.), e também serviu de base para a que o mesmo alltor incluiu em sua obra Aculturação dos Alemães no Brasil (Cia. Editòra Nacional, São Paulo, 1946, págs. 281 e segs.).

(2) Abreviamos os nomes dos diversos Estados, cidades e zonas como segue: Rio Grande do Sul: RG, Santa Catarina: SC, Paraná: P, São Paulo: SP, Minas Gerais: MG, Espírito Santo: ES, Pôrto Alegre: PA, Curitiba: C, Blumenau (antigo município de Blumenau, isto é, todo o vale do Itaja1): Bl, Brusque: Br, Joinville: J, Colônia Rio-Grandense (Município de Assis, São Paulo): Riogr., Lajeado: Laj. Quando mencionamos um Estado e uma região ou certa colônia, queremos dizer que a expressão foi lá encontrada por nós, sem sabermos se é ou não usada também alhures. No caso de não indicarmos zona alguma, supomos que a expressão é geralmente conhecida, sem podermos assegurar isso com absoluta certeza. A sigla RG indica tratar-se de têrmo usado não sòmente no Rio Grankle do Sul, mas também em outras zonas colonizadas por colonos teuto-rio-grandenses, como no hinterland catarinense, em certas regiões do Paraná etc., enquanto $\mathrm{SC}$ significa em geral sòmente a região colonial do vale do Itajaí de Joinville e municípios vizinhos, Brusque, São Bento etc., isto é, o nordeste dêsse Estado.

(3) f. h. = formação híbrida.

(4) p. t. = palavra transferida de coisa conhecida na Alemanha para outra, diferente, no Brasil.

(5) trad. = tradução.

(6) Em certas regiões gaúchas é costume a mocinha oferecer ao namorado na sua primeira visita em casa do pai o Mate-Tee no caso de êle ser benvindo e no caso contrário o chimarrão (amargo). Não sabemos se é costume tomado à população luso-brasileira ou peculiar aos teutos.

(7) Em SC o imigrante novo em português é designado pelos teutobrasileiros "alemão fresco" (tradução literal da designação frischer Deut- 
scher, mas usada em sentido ambíguo, incompreensivel ao recém-vindo). Também dizem em SC galego para imigrante novo.

(8) Al. = Alemanha.

(9) Espécie de palmeira que dá fruto em cachos; cacho de tucum, Tukunkasch, é designação injuriosa para o caboclo ( $\mathrm{SC}$-J.), que usa êsses frutos como alimento.

(10) A palavra vulgar alemã Spatz ou o seu diminutivo são desconhecidos entre os colonos descendentes dos imigrantes do Hunsrück no RG para designar o tico-tico; usam, entretanto, Spatz com a significação de membro viril.

(11) No RG diz-se: "ein Tatu fangen", peçar um tatu, atolar o carro.

(12) Conhece-se também a expressão " "jnen Kwatie im Genick haben", ter um quati na nuca, estar com preguiça; existe em SC-Bl. a designação Barankenkwatie - quati que vive nos barrancos dos rios.

(13) Também usado como nome injurioso para o caboclo.

(14) O joinvilense da cidade insulta o colono com esta palavra.

(15) A batata inglêsa, introduzida pelos colonos alemães no $\mathrm{PG}$, forma a base da alimentação alemã como a feijoada o é da comida brasileira, dando isto origem à alcunha "alemão-batata" expressão usada tarnbém em SC, onde os luso-brasileiros preferem, entretanto, injuriar os seus concidadãos de origem alemã com a palavra "alemão-de-m...". Em SP e SC há o estribilho: "Alemão, c... de pão, come m... com feijão", referindo-se provàvelmente ao fato de terem os alemães ai como em outras zonas introduzido o uso de fabricar e comer pão. Outro produto, introduzido pelo alemão, é a cerveja; não é de admirar, portanto, a alcunha "alemãochope", conhecida antigamente mais do que hoje em SP. - Outro opróbrio em SC é galego, principalmente para o alemão louro.

(16) V. as diversas formações híbridas, usadas como opróbrios.

(17) Nas zonas coloniais e em SP, onde o elemento teuto entra em contacto com o elemento italiano, adotaram-se com os respectivos alimentos também as palavras: polenta, pizza, panetone etc. Por outro lardo, o elemento luso em certas regiões, ao adotar as respectivas comidas e bedidas, tenta aceitar e pronunciar palavras como Apfelstrudel (avestruz), Streusselkuchen, Nusskipfel, Limburger (tipo de queijo), Bock(bier), Malzbier, Bitter, Kirschwasser etc. (V. também a nota 25).

(18) $\mathrm{Na}$ Al. não conheciam o pasto cercado com arame farpado, com porteira, mata-burros etc.

(19) No RG usa-se a frase: "Ihr habt mir schöne Pünsch an!", (Vocè está vestindo um belo poncho!) no sentido de: "Você tem mesmo cara
disso!"

(20) Daí é derivado o verbo verkaboklern, "descer" ao nível econômico, social, cultural e higiênico do caboclo.

(21) As designações da procedência geográfica de uma pessoa são formadas geralmente de acôrdo com os respectivos têrmos portuguêses: Curitibaner, Paulistaner, Joinvillenser (em vez de Joinviller) etc.

(22) Todos os têrmos relativos ao complexo do cavalo foram colhidos no $R G$.

(23) Paralelamente com as expressões portuguêsas usam-se, p. ex., Zügel, Sattel, Pelz, Stiefel, Gurt.

(24) Usa-se no RG a frase "Du kannst mich am Fumm riechen!" Você me pode cheirar no fumo (i. é, no membro viril).

(25) A convivência de alemães ou teuto-brasileiros com luso-brasileiros não podia deixar de influenciar com alguns traços, mesmo que relativa- 
mente raros, a língua portuguêsa. Do dialeto dos imigrantes alemães do Hunsrück provêm, por exemplo, Schmier, têrmo aceito pelo elemento luso-brasileiro do RG como chimia a ximia, doce de colher em estado semi-sólido, feito de garapa e frutas, como laranjas, pêssegos, ameixas etc. Outros designativos de alimentos e bebidas passaram do alemão para o português, como cuca (Kuchen, bôlo), svibaque (Zwieback), váfel (Waffel), cúmel (Kümmel), biter (Bitter), quirche (Kirsch), chope (Schoppen), Malzbier, Bockbier, chiluque (RG; Schluck, trago de cachaça), lingüiça de Blumenau ou Blumenauer ( $\mathrm{P}-\mathrm{C}, \mathrm{SP}$ : lingüiça defumada, ('omo é feita na Al., antigamente exportada de Blumenau), vinavirste $(\mathrm{P}-\mathrm{C}$, Wiener Würstchen). Nos cardápios encontramos também palavras como Sülze, Bismarckhering, rolimopes (Rollmops), Tilsiter, Limburger etc. No $R G$ e em SC é conhecida também a palavra fristique (Frühstück, refeição entre o café da manhã e o almôço). Uma palavra muito divulgada no RG (desconhecida, aliás, em SC) é Kerb (masc., em alemão fem.), que significava primitivamente a festa popular do Padroeiro da igreja local, realizada nas zonas coloniais de domingo até quarta-feira à noite com música, foguetes, bailes e outros divertimentos populares. O costume foi introduzido pelos colonos oriundos do Hunsrück. Hoje em dia, Kerb significa qualquer festa popular do tipo descrito. - A palavra zigue-zague (Zickzack) é usada como grito de vitória ou de combate pelos futebolistas e esportistas ( $R G$ ) e para certo tipo de passamanes; conhece-se até o verbo zigue-zaguear. - Elementos cuja origem alemã não é mais identificável são, segundo nos informaram, bichuá (RG; ein bisschen schwach, um tanto fraco, falando do fumo em corda), serrigote ( $R G$, sehr aut, muito bom, ótimo; lombilho melhorado e estofado, introduzido pelos alemães, que recomendavam o seu produto aos compradores lusos com as palavras alemãs sehr gut), bitruca (SC, betrunken, bêbado). Nas camadas sociais mais elevadas usa-se a palavra Fräulein (SP, senhorita; governante alemã), Frau (RG, tratamento usado com o nome de família), Herr (idem), Kindergarten (jardim de infância), Krach (quebra financeira), Lied. Existem também alguns vocábulos de sentido político, militar e científico usados em português, tais como Kaiser, fuera (Führer), Anschluss, Blitzkrieg ou sòmente Blitz, Luftwaffe, Landwehr, talvegue (Talweg), Leitmotiv, Hinterland, Föhn etc.

(26) Não nos referimos aqui à pressão exercida pelo Estado quanto aos nomes geográficos, substituindo muitas designações populares alemãs por denominações portuguêsas e indígenas, como também à exigência quanto aos nomes dados às crianças. Trata do primeiro assunto um artigo de Theodor Kadletz na revista "Deutsche Volksforschung" e do segundo uma pesquisa muito interessante do Dr. Erich Fausel na mesma revista alemã. 